Max-Planck-Institut für demografische Forschung

Max Planck Institute for Demographic Research

Doberaner Strasse $114 \cdot$ D-18057 Rostock $\cdot$ GERMANY

Tel +49 (0) 3812081 - 0; Fax +49 (0) 3812081 - 202;

http://www.demogr.mpg.de

MPIDR WORKING PAPER WP 2002-009

FEBRUARY 2002

\title{
Work Lives amid Social Change and Continuity: \\ Occupational Trajectories in Monterrey, Mexico
}

Patricio Solís (patricio@prc.utexas.edu)

Francesco C. Billari (billari@demogr.mpg.de)

(C) Copyright is held by the authors.

Working papers of the Max Planck Institute for Demographic Research receive only limited review. Views or opinions expressed in working papers are attributable to the authors and do not necessarily reflect those of the Institute. 


\title{
Work Lives amid Social Change and Continuity: Occupational Trajectories in Monterrey, Mexico ${ }^{1}$
}

\author{
Patricio Solís \\ Population Research Center \\ Department of Sociology \\ University of Texas at Austin \\ 1800 MAI \\ Austin, TX 78703 (United States) \\ e-mail: patricio@prc.utexas.edu \\ Francesco C. Billari \\ Research Group on the Demography of Early Adulthood \\ Max Planck Institute for Demographic Research \\ Doberaner Str. 114 \\ D-18057 Rostock (Germany) \\ e-mail: billari@demogr.mpg.de
}

\footnotetext{
${ }^{1}$ Support for this research was provided by The Population Council, the Andrew W. Mellon Foundation, the Population Research Center of the University of Texas at Austin, and the Max Planck Institute for Demographic Research. Address correspondence to Patricio Solís, Population Research Center, University of Texas at Austin, 1800 MAI, Austin, TX 78703, or e-mail to patricio@prc.utexas.edu. We thank Susann Backer and Jenae Tharaldson for comments on a previous draft. The views expressed in this paper are attributable to the authors and do not necessarily reflect those of the institutions they belong to.
} 


\begin{abstract}
In this paper we use sequence analysis to study the occupational trajectories between the ages 14 and 30 for men in Monterrey, the third largest city of Mexico. We build typologies of trajectories based on life-history data and then explore changes in the frequency of these "typical" trajectories over time as well as differences across socioeconomic groups. Cohort trends reveal more continuities than changes in occupational trajectories, despite the structural changes experienced by the city in the last two decades. Career patterns are closely related to family origins and educational attainment, thus suggesting the continuing importance of both ascribed and attained characteristics on occupational outcomes.
\end{abstract}

\title{
INTRODUCTION
}

Occupational trajectories and job mobility have long been central issues in sociological research. Most of the literature has focused on trends observed within and among developed countries. More unusual have been studies on the occupational histories of individuals in developing societies. In the particular context of Latin America, there are remarkable antecedents of research on occupational mobility based on life-history data (for the case of Mexico, see Balán, Browning and Jelin (1973) and Muñoz, Oliveira, and Stern (1977). But most recent research is either restricted to the analysis of structural mobility using cross-sectional data (Klein and Tokman 2000; Koch 1999; Roberts and Oliveira 1994), to intergenerational mobility trends (Behrman, Gaviria, and Székely 2001) or, in rarer cases, to mobility between two moments in individuals' lives (Escobar undated). Although these studies illustrate some of the most remarkable trends in occupational mobility in the region, they generally lack a more comprehensive perspective on the structuration of occupational trajectories during the life course.

The aim of this paper is to study the occupational trajectories of men in Monterrey, the leading economic pole of northern Mexico and the third largest city of 
the country. There are several substantive reasons to be interested in occupational trajectories in developing societies. From a theoretical standpoint, studies on occupational life courses and mobility may be enhanced by incorporating the complex cases of developing societies into the already existing research on developed countries. Occupational life courses are shaped by the interplay of labor market structures, state institutional regulations, and individual choices (Mayer 2001), but cross-national studies in job mobility have rarely analyzed this interaction of determinants, and the limited research on the subject (see for example Di Prete et al. (1997; 2001; DiPrete et al. 2001)) is restricted to developed countries. Developing societies are a more complex research challenge because career patterns are likely to reflect not only the particular institutional arrangements of single cases, but also to reflect larger internal heterogeneities in labor markets and state regulations. In this sense, the analysis of occupational trajectories in developing societies may provide interesting points of contrast that are helpful in further understanding institutional influences on occupational life courses.

In the context of Mexico, a more comprehensive view of occupational trajectories is also relevant because it may serve to trace some of the effects of recent structural changes on individual life courses. Like most Latin American countries, Mexico suffered a period of acute economic recession during the 1980s, followed by aggressive liberalization and market reforms during the 1990s (Smith and Korzeniewicz 1997; Clavijo and Valdivieso 2000). At least in the short-term, the social effects of these changes have been negative, particularly in terms of income inequality (Cortés 1998; Alarcón 1994) and poverty levels (Boltvinik and Hernández Laos 1999; World Bank, ADB, IADB, IMF, and EBRD 2001). But the consequences of these transformations on occupational careers and mobility prospects are less clear, first, because there are strong regional differences associated with the degree of success of local economies in the process of adaptation to market reforms, and second, because the short-term negative 
effects of the crisis and restructuring period may be confounded by long-term trends in the structuration of labor markets. Monterrey is an interesting case for studying the impact of these long-term trends in occupational trajectories because its relatively advanced industrialization made it particularly vulnerable to the structural crisis of the 1980s (Pozos Ponce 1996; Pozas 1993), and because it represents a "successful" example of adaptation to the market reforms of the 1990s (Cerutti 2000; Pozas 1999).

We analyze the occupational trajectories of men between the ages of 14 and 30 . The data come from a representative survey which was applied to 1,200 men and carried out in $2000^{2}$. The survey includes complete occupational histories. This allows us to analyze occupational careers as a whole, starting with the entry into work and continuing with each successive occupation until age 30. Our strategy consists of building typologies of trajectories based on the set of techniques known as sequence analysis (Abbott 1995). Using optimal matching, we obtain clusters of career patterns and then we explore their characteristics as well as changes in their prevalence over time and across socioeconomic groups.

The paper is organized as follows. In the next section, we discuss the utility of a holistic approach for the study of occupational careers. Then, we describe the institutional setting of Monterrey, some of the most important social and economic transformations of recent decades, and how these circumstances may have affected occupational trajectories. The specific methodological features of sequence analysis and the characteristics of the data set are the subject of the methods and data section. Next, we present our results, including the analysis of cohort and socioeconomic differences in career patterns. The paper concludes with a summary of our most important findings and a brief discussion of the advantages and problems of the application of sequence analysis to occupational-history data.

\footnotetext{
${ }^{2}$ The survey was designed to replicate the original study on occupational histories carried out by Balán, Browning and Jelin (1973) back in 1965. Both surveys interview only men. That is the reason why we do not include women in the analysis.
} 


\section{A HOLISTIC APPROACH TO OCCUPATIONAL CAREERS}

The study of occupational mobility has a long-standing tradition in sociological research. From its origins, the field has been dominated by studies that focus on intergenerational mobility or, alternatively, on measures of mobility obtained by contrasting occupations at two different moments in individual lives. More recently, however, the parallel development of the life course research stream and event history analysis has produced a shift of emphasis from long-term mobility to individual events within occupational trajectories. Thus, for example, a number of studies have utilized life-history data to explore the effects of social, family and individual determinants of job shifts (Blossfeld, Hamerle, and Mayer 1989; Shavit, Matras, and Featherman 1990). Others have focused on different events of occupational trajectories, such as the transition to unemployment (Sørensen 1990), or the timing of entry into the labor force (Bernardi 2000) ${ }^{3}$.

Implementation of this "event-centered" approach has greatly increased the potential of research dealing with occupational mobility and its interrelationship with trajectories and transitions in other domains of the life course . With the help of event history analysis, it is possible to study the mutual interdependencies between occupational transitions and parallel careers in other spheres of the life course, as well as the matching of occupational trajectories of interrelated individuals, such as couples. In addition, one can analyze the impact on occupational mobility of variables situated at different levels of aggregation, such as individual characteristics, family determinants, and broader economic and social circumstances. The flexibility of event history analysis even allows for consideration of previous occupational trajectories and transitions, such as the age of entry into the labor force, occupational mobility, or job experience as determinants of future events in individuals' occupational lives (Blossfeld and Rohwer 2002).

\footnotetext{
${ }^{3}$ A recent account of the literature on occupational mobility and event history analysis can be found in Blossfeld \& Rowher (2002)
} 
However, by focusing on what Elder (1985) has called the "short-view in analytical scope," researchers may lack a holistic perspective of occupational trajectories as meaningful conceptual units. Take as an example the subject of this paper, namely trajectories from the start of occupational lives to the end of early adulthood. An event-centered approach would require the partition of these trajectories in individual transitions, such as the entry into the labor force, individual job shifts, or the transition from employment to unemployment. The separate analysis of each of these events may produce significant insights into the study of occupational careers, but it does not allow researchers to fully visualize their possible interdependence within an individual's career. It is reasonable, for instance, to think that a late age of entry into the labor force may be associated with a career start in a high-level occupation, which in turn may be linked to later job stability and low occupational mobility. Alternatively, an early entry into the labor force may be associated with a start in a lower-manual position which leads either to upward mobility or to no further occupational attainment, generating two alternative paths in young individuals' occupational careers. Thus, the event-centered approach is extremely useful for exploring the determinants of individual job transitions, but it is not well suited for producing an overall account of the succession of these transitions across time nor for their integration into entire occupational careers.

In our view, the study of entire occupational careers as conceptual units may lead to interesting findings which would complement those obtained by "eventcentered" approaches, such as event history analysis. There are at least two theoretical ways of justifying the interest on complete life courses and, in this particular case, on entire occupational trajectories (Billari (forthcoming)). First, complete life courses can be interpreted to be at least partially the outcome of long-term strategic individual planning. The hypothesis of a holistic view of the life course present in the behavior of individuals themselves is common to theoretical developments in economics (Deaton 
and Muellbauer 1980 Ch. 12 ; Camerer 1995), sociology (Giddens 1991), and psychology (Heckhausen 1999). For these theoretical approaches, it is not only useful but also necessary to adopt a perspective with the entire life course as a conceptual unit.

Second, even if one is not eager to take up such a strong theoretical assumption and instead adopts a view in which the life course is thought of as being a contingent result of subsequent events, there are still reasons to consider entire occupational trajectories as meaningful units of analysis. Entire occupational trajectories may serve to summarize the past occupational history of individuals and provide insights not only into the timing of single events, such as the entry into the labor force and subsequent job shifts, but also into their sequencing (occupational mobility paths), the duration of time spent in each occupation, and the timing between occupational transitions. Furthermore, the analysis of similarities and differences in occupational careers might result in the identification of "typical" occupational trajectories that can be used to describe the occupational experiences of individuals with different social and demographic characteristics, as well as in comparative research across countries, regions, or cohorts.

The promise of a holistic approach for occupational careers has been somewhat hampered by the technical and methodological difficulties arising from the analysis of entire sequences of events. However, the introduction of the set of techniques known as sequence analysis offers new alternatives for managing such information. In this paper we use sequence analysis to study the occupational trajectories of Monterrey men.

\section{THE CASE OF MONTERREY}

Located only 140 miles south of the United States border, Monterrey is the leading economic pole of northeast Mexico. With more than 3.2 million residents in the year 2000, the city's population is only exceeded by those of Mexico City and Guadalajara, the other two large metropolitan areas of the country. The industrial development of Monterrey dates back to the $19^{\text {th }}$ century, with the opening of a brewing 
factory and the first modern still mill in Latin America (Cerutti 1992). From the decade of the 1940s, the city's economic growth has been increasingly tied to the national economy. Between the 1940s and the 1970s, Mexico experienced an accelerated process of industrialization and urbanization, sponsored by protectionist policies that provided support to the expansion of manufacturing and reserved the internal market for nationally produced goods. In this context of "inward-looking" economic growth, Monterrey's industrial base expanded considerably. However, by the beginning of the 1980s this model of economic growth collapsed. The city entered a decade of recession, with negative consequences for labor, and particularly for real wages, which even today remain at lower levels than those observed at the beginning of the 1980s. By the beginning of the 1990s, the most dramatic effects of the crisis were over. The major local firms that survived the recession had restructured their activities and the economy of the city experienced a second period of economic growth, this time based on the expansion of economic activities to external markets (Cerutti 2000; Pozas 1999). However, there is considerable debate about whether this renewed economic expansion has brought equal benefits for firms and labor, especially in light of the persistently low wage levels and the precarious labor conditions.

Readers informed about the recent socioeconomic development of Mexico and Latin America may find this description familiar, because in several ways it summarizes the overall trends observed in the region during the last two decades. In this sense, the case of Monterrey is illustrative of some of the challenges faced by Latin American economies after the end of the "inward-looking" period of economic development. But there are also other features of Monterrey socioeconomic development that are common to many Mexican and Latin American cities. Three of these features are particularly relevant for their impact on labor markets and potential effects on occupational trajectories. 
The first of these features is the increase over time in formal education, prompted by the expansion in the supply of public schooling at all education levels. In the particular case of Monterrey, this increase has not been limited to primary education, but also to middle-level and college education. The result has been a radical change in less than a life-time in the schooling profile of Monterrey residents: the proportion of males between ages 21 and 60 with less than primary education decreased from $50 \%$ in 1965 to $9 \%$ in 2000 . On the other extreme end of the distribution, the fraction obtaining at least a year of college education increased from $6 \%$ to $26 \%$ during the same period. ${ }^{4}$ This radical transformation may have been associated with important changes in Monterrey residents' occupational trajectories not only because the accumulation of human capital is an important determinant of occupational prospects, but also because the increase in the attendance of middle-level schools and college may have produced a delay in the entry into the labor force and altered the timing of further occupational mobility.

A second relevant feature is the changing role of rural migration in population growth and occupational mobility. Up until the 1980s, rural migrants contributed a substantial fraction of the growth of Monterrey's population. Many of these migrants performed farm activities in their communities of origin and were attracted by the city's increasing job opportunities, especially in manufacturing, which, as we have described before, was the most dynamic sector during the "inward-looking" period of economic growth. The continuous flow of rural immigrants to the city meant that many young individuals entering the local labor market were either children of peasants or youth who had already started their occupational careers in farm activities at the bottom of the occupational hierarchy. Thus, farm origins shaped the occupational careers of a large proportion of residents.

\footnotetext{
${ }^{4}$ The figures were obtained from Balán et. al (1973) and from the Monterrey sample of the National Survey of Urban Employment (ENEU) for the third quarter of the year 2000
} 
This situation has changed in recent times, mainly as a result of two factors. First, migration to Monterrey has considerably decreased in the past two decades. This is a trend observed not only in Monterrey, but also in Guadalajara and Mexico City, all sites which have seen substantially reduced rates of social growth since at least the 1980s (Partida Bush 1994; Solís 1997). Second, the process of urbanization in Mexico has also altered the dominant patterns of internal migration, from rural-urban to urbanurban (CONAPO 2001). In Monterrey, these two trends have resulted in the reduction of the proportion of the population with rural origins: the proportion of men who migrated to the city from rural and small urban communities (less than 20,000 residents) was $50 \%$ for the birth cohorts $1940-1949$ and only $24 \%$ for the cohorts $1960-1969 .^{5}$ Consequently, the proportion of Monterrey residents who started their occupational careers in rural communities has also declined, reducing the frequency of one of the typical paths of occupational mobility observed until the recent past.

A third common feature of Monterrey and other Mexican cities is the continuing segmentation of labor markets. The informal economy, made up of the self-employed (excluding professionals), workers without formal contracts in low-productivity enterprises, and non-wage workers, accounts for a significant proportion of the working population ${ }^{6}$. To the informal sector, long present in many Latin American cities, it is necessary to add a more recent development: the "flexibilization" of labor conditions among workers in the formal sector (Klein and Tokman 2000). "Flexibilization" has taken several forms, but two of the most significant are a shift from permanent to temporary labor contracts and the reduction of worker benefits. This segmentation in formal, informal, and "flexibilized" labor conditions may affect the structuring of occupational trajectories in many significant ways. Both informal labor conditions and "flexibilization" impose barriers to the institutionalization of occupational careers.

\footnotetext{
${ }^{5}$ The proportions are obtained from the 2000 Monterrey Occupational Mobility and Life Course Survey. More on this survey below.

${ }^{6}$ There is a vast literature on the informal economy in Latin America. See Portes et al. (1989), Rakowski (1994) and Cross (1998). Roberts (1989) and Beneria (1989) discuss the interrelationship between formal and informal jobs in occupational trajectories.
} 
Individuals in the informal sector are not subject to age regulations for entering and exiting the labor force, nor to the age- or antiquity-based promotion systems characteristic of intra-firm labor markets. These latter conditions do not apply to workers with "flexibilized" labor contracts either, since they do not accumulate years of service and are not eligible for internal promotions as their counterparts with permanent job positions are. Moreover, the formal and informal sectors are not necessarily isolated from each other. Some individuals may follow entire occupational trajectories in one sector, but many others switch between formal and informal jobs once or several times during their occupational lives. In sum, the situation is one of heterogeneous work conditions, which are likely to reflect more diverse and less standardized occupational trajectories in relation to those observed in more regulated institutional settings.

The deficiencies of the labor markets and the state in providing job security and channels for mobility are also related to another feature commonly mentioned as characteristic of Mexican society: the importance of social capital, and particularly of family ties, as an informal resource influencing occupational performance and ultimately affecting job mobility. In a context where labor regulations are barely enforced and state-based social insurance programs are extremely limited, the family remains the most important resource to reduce work uncertainty and to deal with the potential hardship produced by structural adjustment. This was very evident during the economic crisis of the 1980s, when low- and middle-class urban families dealt collectively with economic strain and family members often adjusted their work status to contribute to the domestic economy (González de la Rocha 1994; Tuirán 1993; Selby, Murphy, and Lorenzen 1990). But the influence of the family on individuals' work lives is not limited to moments of economic hardship. In a context of institutional uncertainty, assets of all kinds provided by the family of origin may have great importance in defining occupational prospects and mobility, especially among young individuals starting their occupational careers. In this sense, it is reasonable to expect a 
close relationship between the characteristics of the family of origin and men's early occupational careers.

In sum, Monterrey illustrates how secular socioeconomic development trends, segmented labor markets, and recent structural adjustments all combine to affect the modern urban settings of Mexico and Latin America. The economic restructuring and market reforms of the end of the 1980s and of the 1990s may have introduced significant transformations in Monterrey's productive structure, but there are also elements of continuity, such as the gradual increase in education, the continued segmentation of labor markets, and the relative absence of social insurance programs, which were present before the 1980s and remain an important force affecting occupational careers. Several questions arise in relation to occupational trajectories: is it possible to identify "typical" career patterns from the diversity of occupational trajectories of men? Have these "typical" career patterns changed over time? How are family origins and attained characteristics such as schooling related to occupational trajectories?

\section{METHODS AND DATA}

With these questions in mind, we analyze the occupational trajectories of Monterrey men in this paper. We build typologies of trajectories using sequence analysis, a set of techniques originally introduced to the social sciences by Abbott (for a review, see Abbott and Tsay (2000) and Abbott (1995)). In the following sections we present a brief description of sequence analysis, discuss some methodological aspects of the application of these techniques to our research problem, and introduce our data source.

\section{The optimal matching procedure}

The basic principle behind sequence analysis is to represent each life course or trajectory in the life course as a 'word' or, to be precise, as a string of characters. Each 
character in this string represents a discrete unit of time spent in a particular state. Let us take as an example twelve months in the occupational trajectory of three individuals, distinguishing only between two states: unemployed (U) and employed (E). These three occupational trajectories might be represented as follows:

\section{Individual 1: E E E E E E E E E E E E}

\section{Individual 2: U E E E E E E E E E E E}

\section{Individual 3: U U U E E U U E E E E E}

In these three hypothetical trajectories, individual 1 spends the complete year employed, individual 2 experiences unemployment during the first month and then is employed for the rest of the year, and individual 3 experiences two periods of unemployment, between the first and third month and then between the sixth and seventh month of the year. There are several analytical strategies to study life history data in the form presented above ${ }^{7}$. In this paper we focus on clusters analysis applied to dissimilarities between cases, which were computed using optimal matching analysis (OMA), a method originally created for the alignment of sequences in the biological sciences.

The goal of optimal matching is to compute a matrix of dissimilarities between pairs of sequences. The dissimilarity between two sequences is proportional to the cost of transforming one sequence into the other one. This transformation is performed through three basic operations: insertion (a state is inserted into the sequence); deletion (a state is deleted from the sequence); and substitution (a state is substituted by another one). To each basic operation a specific cost is assigned ${ }^{8}$. The distance between two sequences can thus be defined as the minimum cost of transforming one sequence into the other, where the total cost is obtained by summing the costs of each elementary operation. Thus, for example, if we assign a cost of two units for insertion and deletion

\footnotetext{
${ }^{7}$ These include the graphical representation of sequences (see, for instance, the descriptions provided by BioBrowser (Statistics Canada 1999), and the monograph by Wehner (1999).

${ }^{8}$ The assignment of these substitution and "in-del" costs is a crucial step in the optimal matching procedure, because the estimated distance between sequences depends directly on these costs. Later we discuss this in greater detail.
} 
costs and of one unit for substitutions, the cost of transforming sequence one into sequence two in the example above would be 1 unit (equivalent to substituting $\mathrm{E}$ by $\mathrm{U}$ in the first segment of the sequence), and the cost of transforming sequence two into sequence three would be 4 units (four substitutions, in segments 2, 3, 6, and 7). Specific dynamic programming algorithms assure that the minimum cost is effectively found (Sankoff and Kruskal 1983; Waterman 1995) ${ }^{9}$. The result of applying this procedure to each pair of sequences is a distance matrix, which summarizes the differences among entire sequences of events. Finally, this matrix can be used as the input for any kind of statistical analysis requiring proximity data (e.g. cluster analysis or multidimensional scaling).

Most of the recent sociological literature analyzing entire sequences of life course events makes use of optimal matching. The technique has been applied with good results to topics as diverse as the careers of musicians in the $18^{\text {th }}$ century (Abbott and Hrycak 1990), upward mobility to the service class (Chan 1995), occupational trajectories in early and middle adulthood (Halpin and Chan 1998), careers among executive women (Blair-Loy 1999), and the succession of events constituting the transition from school to work (Rohwer and Trappe 1999; Scherer 2001). However, it must be acknowledged that optimal matching analysis is still in its infancy and that there are many substantial aspects of the technique that remain to be improved in order to incorporate it as a conventional tool for the study of occupational mobility. ${ }^{10}$ One challenge is to demonstrate that OMA can systematically produce meaningful results with large samples. Virtually all the analyses above are based on small samples (the exception is Halpin and Chan's piece), and there might be some doubts about the usefulness of the technique when applied to large samples. Perhaps a more substantial problem is that the technique is well-suited for describing occupational careers but it has

\footnotetext{
${ }^{9}$ In this application we used the OMA algorithms implemented in the TDA package, a public domain software available at the following URL address: http://steinhaus.stat.ruhr-uni-bochum.de/tda.html. See also Rohwer \& Pöter (1999).

${ }^{10} \mathrm{Wu}(2000)$ makes a detailed critical review of the most relevant methodological problems accruing in optimal matching procedures.
} 
not been possible so far to use it for causal analysis. A possible solution to this problem is the further utilization of clusters of similar careers both as independent and dependent variables (Abbott and Hrycak 1990).

\section{Data}

The data utilized for this study comes from the "Monterrey Occupational Mobility and Life Course Survey"11. This survey was administered to 1,200 men between the ages of 30 and 60 during the second semester of 2000 . The principal aim of the survey was to collect similar information to that obtained by Balán and colleagues (1973) in their classic 1960s study about spatial and occupational mobility in Monterrey, with the ultimate objective of contrasting recent occupational mobility patterns to those observed in the past ${ }^{12}$. Respondents were asked for their complete occupational, residential, and family histories, as well as for detailed information on their educational trajectories, their family background, and current job satisfaction.

Occupational histories include the beginning and ending months of each occupation, as well as some characteristics of the occupation, such as the name, principal activities performed in the job, sector, and type of contract. This information was used to obtain the occupational trajectories of men between the ages of 14 and 30 . We utilized a classification of eight occupational categories (Table 1). This classification is based on the classical double division between manual/non-manual and skilled/unskilled activities, and distinguishes between a number of groups within these four large categories. It has several parallels with that proposed by Erikson and Goldthorpe (1992) for industrial societies, but with some modifications to account for data limitations and the particular characteristics of stratification in urban Mexico. Two of these modifications are the assignment of technicians to the category of skilled non-

\footnotetext{
11 "Encuesta Sobre Movilidad Ocupacional y Curso de Vida en Monterrey 2000".

${ }^{12}$ A description of the survey questionnaire, the sample design, and other technical aspects of the 2000 survey is provided by Solís ((draft)). Both the data set and the technical documentation of the survey are available upon request.
} 
manual workers and the allocation of all workers in agricultural activities into the lowest category. In the first case, the change was made after an analysis of wages and other occupational characteristics revealed that technicians' labor conditions are closer to those of school professors, office workers, and other unskilled clerical workers than to those of professionals and managers (Solís (draft)). In the case of farm workers, there is not enough information about the characteristics of their farm activities to distinguish between farm owners, farm laborers, and peasants. Since most of the population in agricultural activities are either farm laborers or peasants, we decided to classify the entire group in the lowest occupational category.

\section{[ TABLE 1 ABOUT HERE ]}

The occupational trajectories of 1,019 of the 1,200 men $^{13}$ interviewed in the Monterrey survey were coded on a monthly basis, using a classification of ten different states. Eight states correspond to the different occupational groups described in Table 1. The other two states refer to periods without an occupation. The first state $(\mathrm{N})$ reflects the time before the start of a working career. It is the state of origin for most of the respondents, but not for all of them as they might have started working before the age of 14. The second state $(\mathrm{O})$ refers to periods out of work after previous occupational experience. We assume states $\mathrm{N}$ and $\mathrm{O}$ to be closely correlated to full-time education exits and entries and, to a lesser extent, unemployment.However, there is no way to establish this with certainty due to the absence of detailed information on educational trajectories and on the activities of men in periods without an occupation.

\footnotetext{
${ }^{13}$ A total of 181 men were excluded from the analysis. Most of them (163) were migrants who arrived in Monterrey after the age of 21.We therefore decided to exclude them because their occupational trajectory reflects to a larger extent the characteristics of their community of origin and not their occupational experience in Monterrey. The rest were excluded due to missing data on their occupational trajectories.
} 


\section{Substitution costs and the clustering method}

The next step in performing the optimal matching procedure was to define substitution, insertion, and deletion costs. As we mentioned before, different assumptions about the substitution and "in-del" costs may significantly affect the OMA results, because the calculation of distances between occupational sequences depends directly on these costs. Thus, as Chan (1995) argues, decisions about substitution costs must be grounded in our conception of theoretically important divisions between occupational groups. In the absence of an elaborated conceptual framework detailing these divisions for urban Mexico, we follow a common practice in mobility and stratification research in this article and adopt a four-group hierarchy of occupations, with higher non-manual occupations at the top (group I), followed by lower non-manual (II to IV), higher manual (V) and lower manual occupations (VI to VIII) ${ }^{14}$. We assign substitution costs based on this hierarchy of occupations. We also assign an additional cost to substitutions trespassing the farm/manual/non-manual boundaries, following the assumption that these boundaries represent significant thresholds in mobility within occupational trajectories.

The resulting matrix of substitution costs is presented in Table 2. The smallest cost (1) is assigned to substitutions within the lower manual (groups VI and VII) and lower non-manual (groups II to IV) categories. The rest of the substitution costs is obtained by summing the number of boundaries crossed in the double-hierarchy mentioned above. Thus, for example, a substitution between IV and V has a cost of 3 units, which is the sum of the minimal substitution cost (1), the cost of crossing the lower non-manual/higher manual boundary, and the cost of crossing the nonmanual/manual threshold. According to this logic, the highest substitution cost (6) is assigned to exchanges between farm occupations (VIII) and higher non-manual

\footnotetext{
${ }^{14}$ The empirical evidence for Monterrey indicates that this hierarchy of occupations exists in aspects such as wages, schooling, standard of living, cultural consumption, and life-styles (Solís (draft)). It must be mentioned that there is a trend towards the reduction of wage differences in recent decades, particularly between lower non-manual and manual occupations. However, the wage gap between occupational groups persists, as well as differences in the standard of living.
} 
occupations (I). This cost is the result of adding the minimum substitution cost (1), the number of boundaries crossed in the four-level hierarchy (3), and the number of boundaries crossed in the farm/manual/non-manual hierarchy (2). Thus, this substitution matrix emphasizes the differences in occupational levels between occupational trajectories, and particularly the distinction between farm, manual, and non-manual occupations.

The matrix also includes the two "out of work" states: not yet in the labor force $(\mathrm{N})$ and temporarily out of work $(\mathrm{O})$. We assigned the maximum cost of 6 to all substitutions involving these two states. In the case of "N," the decision is based on our interest in exploring the effect of the age of entry into the labor force in later occupational trajectories. By assigning a large value to substitutions between " $\mathrm{N}$ " and all other states, we emphasize the distinctions between the occupational trajectories of men with early and late entries into the labor force. A similar logic explains the decision of assigning a large value to substitutions between " $\mathrm{O}$ " and the other states. Occupational careers with long or frequent periods out of work reflect irregular job trajectories, possibly due to returns to full-time education, unemployment or job instability. The high costs of substitution serve to distinguish intermittent occupational sequences from more stable trajectories.

In relation to insertion and deletion costs, the common practice is assigning similar costs to all kinds of substitutions. However, there is debate as to whether these costs should vary depending on the proximity of occupations, as substitution costs do. In this particular application, we decided to avoid any assumption about insertion and deletion costs and to restrict the operations of the optimal matching procedure to substitutions. To do this, we assigned a fixed cost of 6 to "in-del" costs. Since all occupational trajectories in our analysis have exactly the same length (191 months, equivalent to the number of months between the ages of 14 and 30), the practical outcome of this decision is that in-del operations are never utilized in the optimal 
matching procedure because they are as costly as the most "expensive" substitution cost.

The matrix of distances between sequences obtained from the optimal matching procedure was then treated with cluster analysis. Clustering procedures are always complicated because there are many alternative techniques and the outcomes may significantly vary according to which of these methods is selected (Gordon 1999; Everitt 1993). In this application, we chose the Ward method because it utilizes an analysis of variance approach that provides some basis for establishing the number of clusters necessary to obtain a reasonable description of differences in the sequences. Based on this information (Table 3), as well as on our analysis of the internal homogeneity and characteristics of each cluster, we decided to limit our analysis to twelve clusters. The proportion of the total variance ( $\mathrm{r}$ square) explained by these twelve groupings of sequences was 0.759 .

[ TABLES 2-3 ABOUT HERE ]

\section{PATTERNS OF ENTRY INTO THE LABOR FORCE AND OCCUPATIONAL MOBILITY}

Before proceeding to the analysis of entire occupational trajectories, it may be useful to briefly discuss some recent trends and differentials in patterns of entry into the labor force and occupational mobility in Monterrey. As we outlined above, one of the most remarkable features of socioeconomic development in Monterrey and other Mexican cities is the confluence of trends usually associated with the process of modernization, such as the increase in education and the reduction of rural-urban migration, with a persistent segmentation in labor markets and large social inequalities. As a result of these trends, heterogeneity in occupational life courses has persisted, 
despite trends similar to those observed in developed countries in the timing of the most significant occupational transitions ${ }^{15}$.

Consider the differences in men's ages of entry into the labor force (Table 4). Cohort trends reveal a gradual increase in the median age at the time of the first job, from 15.7 years in the birth cohorts $1940-1949$ to 16.8 years in the cohorts $1960-1969$. Increases are slightly larger for the first quartile (13.4 to 14.8 years), perhaps because gains in the attendance of secondary education are larger than those observed at higher educational levels. In general, these trends are consistent with those observed in developed countries after the massive expansion of schooling to secondary and college education (OECD 2001). However, this overall trend is overshadowed by the large differences in men's experiences across socioeconomic groups. Let us first take a look at differences in education. As expected given the connection between the end of educational trajectories and the beginning of occupational careers, there is a clear association between educational levels and the age of entry into the first job. Among men with less than a primary school education, the median age of entry into the labor force is 13.5 years, versus 19.2 years for men who attended college. The extent of this gap can be fully noticed when we look at the differences between quartiles: by 15.4 years of age, $75 \%$ of men with less than primary schooling had already experienced the transition to work whereas it took almost eleven more months (16.3 years of age) for men with a college education to reach $25 \%$ in the proportion experiencing this transition.

The association is very similar when, instead of considering the respondent's own schooling, we take a look at his father's educational attainment. It is important to note that in this case there is not a direct connection between educational and

\footnotetext{
${ }^{15}$ This is well illustrated by retirement. The age of final exit from the labor force has gradually decreased and is concentrated around 65. However, a more detailed analysis shows the limits of this process of institutionalization in the transition to retirement: only around half of the working population is eligible for a retirement pension (Ham 1993), and those without pensions must work until later ages and rely on their families or on their own savings to afford an earlier exit from work (Solís 1996). Thus, segmented labor markets produce heterogeneity in occupational trajectories and represent an institutional barrier for the complete institutionalization of life courses.
} 
occupational trajectories, but only the indirect effects that may come from the influence of the respondent's family of origin on his patterns of entry into the labor force. It is interesting then to find such a strong connection between the father's education and age of entry into work. Among men whose fathers attained less than a primary school education, the average age of entry into the labor force is 15.7 years, compared to 20.4 years for children of men with a college education. These differences also appear when we consider an alternative indicator of social origins, namely the occupation of the father at birth. The average age at entry into the labor force was 15.9 years for sons of men in lower manual occupations, 16.6 years for higher manual, 17.4 years for lower non-manual and 21.3 years for higher non-manual occupations. These figures suggest that family origins, and particularly the social position of the father, are a very important determinant of the timing of the transition to work.

The same is true in relation to the job level at the start of occupational careers, as well as to mobility between the first occupation and the occupation at age 30 (Table 5). In relation to cohort trends, there is more stability than change: around one half of the men entered the workforce in lower manual occupations (groups VI to VIII), a third in lower non-manual jobs (groups II to IV), and less than 5\% started their occupational trajectories as professionals or managers (group I). Also, in the three cohorts, approximately one-fifth of the men experienced long upward mobility ${ }^{16}$, slightly more than one-third had short upward mobility, one-third did not experience any vertical mobility, and the rest underwent downward mobility. It can be noted that the dominant pattern is one of upward mobility and that this situation seems not to have been altered by the structural changes of Monterrey's economy during the past two decades ${ }^{17}$.

\footnotetext{
16 "Long" and "short" mobility refer to job shifts that cross and do not cross the boundary between manual and non-manual occupations, respectively.

${ }^{17}$ Here it is important to distinguish between mobility in occupations and in other dimensions of stratification, such as wages or income. Even when there is a relationship between occupational standing and wages, patterns of occupational mobility do not necessarily resemble those of income mobility (Hauser 1998). In Monterrey, the persistence of high upward mobility has been accompanied by a significant reduction in real wages in all occupational levels, thus suggesting that for recent cohorts upward income mobility is not as frequent as upward occupational mobility (Solís (draft)).
} 
There is, however, a strong correlation between men's socioeconomic status and social origins. Lower schooling levels are associated with lower occupational standings at the start of occupational careers. This association is also present for the father's education and occupation at birth. Finally, there is a positive and strong correlation between the age of entry into the labor force and the level of the first occupation: among men who started working before the age of 14 , the proportion who did it in lower manual occupations was $77 \%$, versus only $8 \%$ of those who started at age 20 or later. Most men with late entries did start in non-manual positions, and a significant proportion $(22 \%)$ did it at the top of the occupational hierarchy, either as professionals or managers. From this trends and those presented in Table 4, it seems evident that the age of entry into the labor force plays the role of an intermediate variable between both men's educational and social origins and their job standings at the start of their occupational lives.

It is more difficult to interpret mobility trends because they do not depend only on occupational opportunities but also on the limits of mobility prospects imposed by the men's original occupation. Thus, for example, men with privileged positions at the start of their occupational careers have limited upward mobility because they are already at the top of the occupational hierarchy. The same can be argued in relation to downward mobility for men who entered in low-level positions. These "ceiling" and "floor" effects may result in misleading conclusions when comparing mobility prospects for groups of men with different profiles of entry into the labor force. A good example is mobility by age of entry into the labor force. Upward mobility (both long- and shortterm) decreases as the age of entry into the labor force increases, not because those who enter work late have lower occupational prospects, but precisely for the opposite reason: their advantage has already manifested in a privileged position at the start of their occupational trajectory. 
The latter point illustrates some of the benefits of a holistic approach to occupational careers. There are evident interconnections between the age of entry into the labor force, the occupation of entry, and later mobility prospects. These interconnections are difficult to disentangle if each of these aspects of men's occupational lives is analyzed separately. Moreover, mobility patterns can be studied in greater detail if, instead of taking two points in individual trajectories, we consider the full sequence of occupations. In the next section we take a closer look at these interconnections between events, as well as at mobility patterns derived from entire trajectories.

\section{[ TABLES 4-5 ABOUT HERE ]}

\section{GROUPS OF OCCUPATIONAL TRAJECTORIES}

The twelve clusters of occupational sequences obtained after the optimal matching procedure and the Ward clustering method are presented in Table 6. The table also presents the percent distribution of cases in the representative sample that fall within each of these twelve groups, as well as the distribution by number of cases (unweighted). There are six predominant groups, each with at least ten percent of cases. Together, these six groups account for $70.3 \%$ of the sample. In contrast, three clusters of trajectories $(10,11$, and 12) group less than $3 \%$ of the cases each.

The first question is whether these clusters produce meaningful groupings of trajectories. To answer this, we contrasted the clusters according to a series of indicators reflecting the main characteristics of occupational trajectories (Table 7). In addition, we produced a graphic representation of a sample of complete occupational trajectories (Figure 1), which facilitates, as a visual aid, the identification of common patterns in each cluster. As an aid for the upcoming description, we also labeled each cluster according to the main features of the occupational trajectories that they represent. 
Most of the men in the first four clusters spent their entire occupational trajectories between ages 14 and 30 in blue-collar occupations. This is evident in Figure 1, where most "life-lines" in these four groups are dominated by different tones of blue and green, the colors representing manual positions. The majority of migrants with farm backgrounds, as well as men who started their occupational careers very early in unskilled positions, are included in these four groups. Together, these four clusters account for close to half of the men's occupational trajectories (46\%), thus reflecting the numerical importance of manual jobs in the occupational trajectories of Monterrey men.

Despite their common occupational trajectories in manual activities, men in the first four clusters differ significantly in two other aspects of their careers: their age of entry into work and their occupational mobility patterns. Clusters 1 and 2 are characterized by a low age of entry (the median ages are 12.9 and 14.5 years, respectively), but diverge in mobility patterns: men in "early unskilled manual" trajectories are less mobile and stay in unskilled manual positions, while men in "early skilled manual" careers show higher mobility rates and tend to follow ascending trajectories into skilled manual positions. The mobility patterns of groups 3 and 4 ("unskilled manual" and "skilled manual" trajectories) are similar to those of groups 1 and 2, respectively, but the difference between these two pairs of clusters is a later age of entry into the labor force: the median age of entry is 4.1 years higher for group 3 than for group 1 (17.0 versus 12.9 years) and 3.2 years higher for group 4 than for group 2 (17.7 versus 14.5 years).

The occupational trajectories grouped in clusters 5 and 6 are significantly different from those in the previous four groups. Men in cluster 5 have origins in bluecollar occupations (94\% started their trajectory in manual positions), but most of them attained white-collar occupations by age 30. These are the men with "long upward mobility" trajectories, or those who started their careers at the bottom of the occupational hierarchy and were able to obtain non-manual occupations. A closer look 
at Figure 1 shows another common element of these occupational trajectories: most of the transitions from manual to non-manual work took place between the ages of 22 and 26. Given that three of every four men in this group entered the workforce before the age of 17 , it can be deduced that in most cases, long upward mobility took place after a period of several years of experience in manual occupations.

Two features characterize the occupational trajectories of men in cluster 6: an early age of entry into work (the median age is 14.5 years) and the predominance of non-manual occupations from very early in occupational careers. The positions of entry for men in this group are diverse: $49 \%$ started in lower-manual occupations, $4 \%$ in higher manual jobs, and $47 \%$ in non-manual positions. Yet, most men with manual origins experienced the transition to non-manual work (there is long upward mobility in $49 \%$ of the trajectories), and they did it early in their lives, as a closer look at the lifelines in Figure 1 reveals. What did these "teenage white-collar" workers do to attain middle-level positions so early in their occupational trajectories? A possible answer to this question can be found in the work opportunities opened by the segmentation of labor markets and the informal economy. Young men can either initiate their careers as family workers in clerical activities (i.e. as office or commerce clerks in a family business), or as informal, underpaid clerical workers in small offices. These kinds of jobs are relatively abundant in Monterrey and, as a result, are particularly appealing to young men., who are willing to accept precarious work conditions in exchange for some income independence, job experience, and perhaps a chance at being promoted to a better position.

If clusters 5 and 6 represent long upward movers, cluster 7 groups men with "long downward mobility" trajectories, or, in other words, those who experienced the transition from manual to non-manual occupations and continued in manual occupations for a relatively long period of time ${ }^{18}$. Compared to clusters 5 and 6 , this group is

\footnotetext{
${ }^{18}$ Since we use the entire occupational trajectory as the unit of analysis, short job spells are not as determinant in defining group membership as the overall shape of the sequence. Thus, men in trajectories
} 
relatively small $(4.6 \%)$, which is consistent with the overall predominance of upward over downward mobility. Most downward movers started their occupational careers as non-manual workers $(62 \%)$, probably in low-level clerical activities similar to those of men in cluster 6 . The rest mainly started in unskilled manual activities (35\%) and experienced manual/non-manual upward mobility before returning to manual occupations. By age 30, 93\% of men in this group were in manual occupations; $60 \%$ had experienced downward mobility in relation to their first occupation, and another significant proportion encountered downward mobility after an initial trajectory of upward mobility in a double upward-downward movement that cannot be registered when mobility trends are derived solely from two moments in individuals' lives, as in Table 7.

The trajectories of men who spent all or most of their occupational lives in nonmanual jobs are mainly grouped in clusters 8 and 9. Despite this common feature, these two groups differ in their age of entry into the labor force (median ages of 17.8 years and 21.7 years, respectively), and occupations of origin (29\% of men in "clerical" careers started in non-manual occupations, versus only $9 \%$ of men in "professional" trajectories). More importantly, the two clusters also diverge in their mobility patterns and, consequently, their occupations of destiny. Half of the men in "professional" careers attained professional or managerial positions by age 30 , versus only $9 \%$ of men in "clerical" trajectories. In fact, cluster 9 illustrates the most common trajectory pattern for men reaching professional and managerial occupations: of all men with top-level occupations at age $30,51 \%$ pertain to this group (proportion not shown in the table).

The last three clusters are the ones with the smallest number of cases, indicating that they are not very frequent among Monterrey men. The cluster of "professional and managers with early entry" groups men who started to work early in their lives (the median age at entry is 15.7 years) and reached professional occupations at some point in

dominated by non-manual occupations will be grouped together, even in cases where there are short job spells in manual positions. 
their careers before the age of 30. This group of trajectories represents an alternative route of access to top-level occupations, different than the more common path of entry at 21-22 years of age in white-collar positions, represented by cluster 9 . In contrast, the cluster of trajectories with "late entry" groups all men who initiated their occupational careers very late in their lives, according to Monterrey standards. The median age of entry into work for this group is 25.3 years ${ }^{19}$. The late starters are mainly professionals and managers, although there are also lower level white-collar workers and some skilled manual workers. The group is characterized by low occupational mobility (57\% did not experience any mobility between the first job and the job at age 30), which may be due in part to the short time span of their occupational careers. Finally, cluster 12 groups men with "intermittent" trajectories, that is, with long periods of time out of work. The fact that only $1.5 \%$ of men are grouped in this category tells us how rare it is to find men with long periods of inactivity after their initial transition to work. There are two reasons to think that these periods of inactivity are more linked to a return to full-time education or to other out-of-work activities than to unemployment. First, there is no unemployment insurance in Mexico, and therefore few men can afford to be unemployed for long periods of time. Second, both the relatively high median age of entry into work (17.8 years) and the patterns of further upward mobility (78\% experienced long upward mobility) suggest both privileged origins and successful occupational careers, two characteristics that are somewhat inconsistent with prolonged periods of unemployment.

\section{[ TABLES 6-7 ABOUT HERE ]}

[ FIGURE 1 ABOUT HERE ]

\footnotetext{
${ }^{19}$ At this age, $98.7 \%$ of Monterrey men had already experienced the transition to work.
} 


\section{OCCUPATIONAL TRAJECTORIES OVER TIME AND ACROSS SOCIAL GROUPS}

Having summarized the most important features of the clusters of occupational trajectories, in this section we present an exploratory analysis of how these trajectories have changed over time and how they correlate to other characteristics of Monterrey men. We limit our scope to the four variables included in Table 4: birth cohort, father's occupation, father's education, and respondent's education. As is usual in the life course approach, we interpret cohort changes in occupational trajectories as reflecting, at least partially, the effects of broader structural transformations on occupational lives. A father's education and occupation at birth let us evaluate the weight of ascription factors as determinants of occupational paths. Finally, the effects of the respondent's own educational level are more associated with individual attainment, although they also partially reflect the relationship between social origins and education.

Table 8 presents the bivariate relationship between these variables and the occupational trajectories of Monterrey men. Inter-cohort changes are not huge, but it is possible to identify a shift from clusters representing very early ages of entry into work to clusters with later ages of entry. Thus, for example, workers in early unskilled and skilled manual trajectories (clusters 1 and 2, respectively,) grouped 31\% of men in the birth cohorts $1940-1949,25 \%$ in the cohorts $1950-1959$, and $20 \%$ in the cohorts 1960 1969. In contrast, the proportion of men in blue-collar careers with later ages of entry into the labor force (cluster 4 ) increased from $7 \%$ to $14 \%$ between the oldest and youngest cohorts, and the proportion of men in "professional" careers (cluster 9) passed from $8 \%$ to $14 \%$. In addition to this trend, it is difficult to find a clear pattern of change between cohorts. We notice a temporary shift in the importance of clusters 5 and 6 for birth cohorts 1950-1959, but it is hard to discern if this is due to actual differences in the 
experience of men or to sampling variations. In sum, the only solid evidence that can be derived from cohort trends is the gradual shift in favor of occupational trajectories with later ages of entry into work.

Table 8 reveals, however, clear differences in men's trajectories according to their social origins, regardless of whether they are measured by the father's occupation at birth or the father's educational attainment. There is a shift from manual trajectories (clusters 1 to 4 ) to non-manual trajectories (clusters 8 to 10) as a father's educational and occupational levels increase. For instance, the proportion in clusters 1 to 4 is $57 \%$ for children of men in lower manual positions, versus only $4 \%$ for sons of men in higher non-manual occupations. In contrast, the fractions in clusters 8 to 10 are $18 \%$ and $78 \%$, respectively. It is also important to note that the weight of the "atypical" clusters 10,11 , and 12 increases among men with higher social origins, suggesting that these infrequent occupational paths are more common among them. In short, men with more advantaged origins tend to concentrate in trajectories characterized by a late entry into work, a high initial occupational level, and high mobility rates from lower non-manual to higher nonmanual occupations. These trends indicate that ascription factors associated with SES origins still play a determinant role in shaping the occupational trajectories of Monterrey men.

A different question is whether there is an interaction between the effects of the father's occupation and education. It is reasonable to think that fathers with "status inconsistencies" between occupational and educational levels exert a different impact on their children's careers than fathers with a consistent status. The disadvantages of lower educational origins, for example, may be offset for children of men who, despite their low schooling levels, were able to attain a high occupation. In order to explore these interaction effects, we constructed a variable grouping men in eight categories, each representing a different combination of the fathers' education and schooling levels. The first four categories represent "consistent combinations," from the lowest to the highest 
educational and occupational levels. The next four categories represent "inconsistent combinations," that is, cases with a high level in one variable and a low level in the other.

The contrast of trajectories according to these categories produces interesting results. First, the influence of the father's characteristics seems to be accentuated among children of men with a consistent educational and occupational status. Consider the case of children of men with a college education and in higher non-manual positions: $66 \%$ are grouped in cluster 9, against $48 \%$ and $54 \%$ when the father's education and occupation are considered separately. Second, children of men with "inconsistent combinations" tend to follow very different trajectories than those with consistent ones. Children of manual workers with a high education level follow upward mobility careers (clusters 5 and 6) more frequently and manual careers (clusters 1 to 4) less frequently, compared to children of manual workers with a low education level. The opposite is true for children of men in higher non-manual positions: the frequency of higher nonmanual trajectories (cluster 9) is greatly reduced among children of men with less than a college education, compared to children of men with a college education.

As it may be expected, occupational trajectories are also related to educational attainment. This pattern is similar to that observed in the cases of father's education and occupation: as schooling levels increase, the proportion of men in trajectories 8,9 , and 10 also increases, and the fraction in clusters 1 to 4 decreases. A part of this association is due to the correlation between family origins and education. However, schooling attainment is not fully determined by social origins ${ }^{20}$. This suggests that a good schooling performance might be one of the shortest available routes to circumvent the negative effects of low social origins on occupational trajectories.

\footnotetext{
${ }^{20}$ Indeed, multiple regression models (not shown) suggest that family origins explain only around a third of the variance in schooling levels among Monterrey men. These models included years of education as the dependent variable, and years of education of both the father and the mother, rural/urban origins, and occupation of the father at birth as independent variables. Several models with different specifications were tested. The maximum $r$ square value obtained in these models was 0.30 , with mother's education as the most important determinant of educational attainment.
} 
The results of the exploratory analysis presented above can be summarized through the application of multiple correspondence analysis, which produces a graphic representation in a lower-dimensional space of the structure of associations among a group of categorical variables (Clausen 1998; Weller and Romney 1990). Instead of including father's education and occupation as separate variables, we incorporated them within the correspondence analysis as combined categories, as shown in Table 8. The other variables included are birth cohort and the respondent's education. A solution with two dimensions explains $91.4 \%$ of the total inertia. The first dimension accounts for $74.6 \%$, and the second dimension for the residual $16.8 \%$.

The plot representing the position of the different groups in this two-dimensional space is presented in Figure 2. The father's characteristics are circled, with the "consistent" combinations joined by a line. The twelve clusters of trajectories are in capital letters. Birth cohorts and respondent's educational levels can be identified by their respective labels. The main dimension, (x axis) is primarily correlated to both the "consistent" combinations of father's characteristics and educational attainment. Cluster 9, representing higher non-manual trajectories, and the "atypical" clusters 10, 11, and 12, are clearly associated with college education, as well as with the father's high occupational and educational levels. On the left side of the plot, the clusters representing "full-time" manual careers (clusters 1 and 2) are linked to the oldest birth cohort, less than primary education, and father's low occupational levels.

The remaining six clusters are located in between these "extreme" groups of occupational trajectories. Three trends stand out in relation to these intermediate groups of occupational trajectories. First, clusters 6 and 8 , both representing the careers of men who were able to attain lower non-manual jobs but did not reach a top position, group together with father's "status inconsistencies." In this sense, membership in these two groups of trajectories may reflect an "intergenerational adjustment" in mobility prospects, in a downward direction for children of men combining high-level 
occupations and low education, and in an upward direction for children of men with low-level positions but high schooling levels. Second, cluster 4, and to a lesser extent clusters 3 and 7, group together with secondary and preparatory levels of education and a father's background of less than primary education and higher manual occupations. Finally, men with long upward mobility (cluster 5) are located close to the center of the plot, thus suggesting that they come from a variety of social backgrounds.

\section{[ TABLE 8 ABOUT HERE ]}

[ FIGURE 2 ABOUT HERE ]

\section{SUMMARY AND DISCUSSION}

The main purpose of this paper was to study the occupational trajectories of Monterrey men from the start of their careers to the end of early adulthood. We adopted a holistic approach, applying sequence analysis. In contrast with traditional mobility tables that merely focus on two moments of individual lives, and event history techniques that focus on specific transitions within individuals' occupational careers, sequence analysis offers the opportunity to study entire sequences of events as conceptual units. Our initial question was whether it was possible to use sequence analysis to identify groups of similar occupational trajectories representing the typical work experiences of Monterrey men. A second but equally important question was whether these career patterns varied according to demographic, family, and individual characteristics of men.

The application of optimal matching to individual-level data from a representative sample survey produced twelve groups of occupational trajectories. These groups diverge in several characteristics, the most important being: a) the age of entry into the labor force; b) the occupation at the entry into the labor force; c) the 
pattern of occupational mobility; and d) the timing of occupational mobility. A detailed description of the characteristics of each of these clusters can be found in the respective sections of the paper. Here we will limit our comments to selected general features. A first glance at occupational careers produces four large groups of trajectories: those for which manual occupations are predominant (clusters 1 to 4 ); those where non-manual occupations prevail (clusters 8 to 10); those characterized by long upward or downward mobility (clusters 5 to 7); and "atypical" careers (clusters 11 and 12). However, a more detailed view shows that there are a number of alternative paths within these four wide groups of trajectories. These paths vary according to the age of entry into the labor force (i.e. lower ages in clusters 1 and 2 and higher ages in clusters 3 and 4); the extent of occupational mobility (for instance, higher upward mobility for cluster 9 than for cluster 8 ); the timing of mobility (early upward mobility in cluster 6 versus later mobility in cluster 5); and the direction of mobility (downward mobility for cluster 7, against upward mobility in clusters 5 and 6). Thus, the resulting map of career patterns not only reflects long-term mobility patterns, but also their interaction with other aspects of occupational life courses, such as the age of entry into the labor force and the timing of mobility.

In this sense, the analysis of whole occupational trajectories as conceptual units reveals the interconnections between multiple events in men's occupational lives. The age of entry into the workforce is associated with the position of entry, and this position is in turn an important factor for future mobility prospects. Thus, for example, men entering work late do it more often as non-manual workers. From this advantaged position of entry, mobility prospects are limited to job stability or downward mobility. The group of men in "professional careers" (cluster 9), which represents a large fraction of those who attained professional \& managerial positions, adjusts to this pattern of a relatively high age of entry, high status of entry, and either stability or short upward mobility. The "atypical" pattern of "professionals and managers with long careers" 
(cluster 10) is precisely exceptional because it represents the few who entered early into work and later attained a higher non-manual position. On the other hand, very low ages of entry into the labor force are associated with low-level occupations of entry, and few prospects of upward mobility ${ }^{21}$. Clusters 1 and 2 are illustrative of this pattern of careers, in which the very early entry into work seems to be connected either to an enduring place at the bottom of the occupational hierarchy or to short distance mobility into higher manual positions. It is more difficult to disentangle the interrelationships between age of entry, position of entry, and further mobility patterns for men in long upward and downward mobility careers (clusters 5 and 7), because the decisive factor in the identification of these clusters is precisely the occupational mobility pattern, and not a common age of entry into the labor force.

A different question is whether the frequency of these career patterns has changed over time. In a previous section we outlined the institutional and labor market settings as well as the most relevant transformations experienced by Monterrey in recent decades. Among them, we emphasized the crisis of the 1980s and restructuring in the late 1980 s and in the 1990 s as forces transforming local labor markets. We also mentioned other trends that have prevailed despite recent transformations, such as the segmentation of labor markets, the persistence of income inequality, the increase in education, and the reduction of rural-urban migration. In this context, the inertia of longstanding trends seems to have prevailed over social and economic transformation as determinants of occupational trajectories, or at least that is what can be deducted from the continuity observed in cohort trends. The only remarkable pattern is a gradual decrease in the proportion of men with trajectories characterized by an early age of entry into the labor force. This transformation is very likely associated with the increase in full-time secondary and preparatory schooling during recent decades.

\footnotetext{
${ }^{21}$ The exception is cluster 6, which, as we mentioned above, is likely integrated by men who entered into the labor force in informal service positions, such as sales clerks or "office boys."
} 
We also explored the effects of ascribed and attained traits on career patterns. Our results suggest that there is a strong correlation between family origins and occupational trajectories. Career patterns leading to non-manual positions are considerably more frequent for men with fathers in advantaged occupational and educational positions; conversely, men with entire trajectories in manual occupations come more often from a disadvantaged family background. Moreover, we gave evidence pointing to the existence of interaction effects between the father's characteristics: children of men with "inconsistent" combinations of educational credentials and occupational positions tend to follow different career patterns than those with consistent combinations. On the other hand, there is also a solid connection between educational attainment and occupational trajectories, which cannot be entirely attributed to the indirect effect of social origins. In sum, these results indicate that both ascribed and attained characteristics exert a strong influence on the career patterns followed by Monterrey men. How determinant each of these factors are and how their effects have changed over time are questions that cannot be answered with the exploratory approach we have chosen in this paper, but these questions certainly open interesting avenues of inquiry for future research.

From a methodological standpoint, the application of sequence analysis allowed us to identify some common patterns in occupational trajectories among Monterrey men. Our results are representative of some of the advantages and disadvantages of this method when applied to studies on careers and occupational mobility with middle-sized and relatively heterogeneous samples. An obvious advantage is that it helps to reduce in a small number of groups the numerous variants that job trajectories may take at the beginning and during the first years of occupational lives. As we have emphasized in this paper, these variants are not limited to the type of occupation, but also to the timing of entry into work and the timing of occupational mobility. If we also consider all the possible variations produced by temporary "atypical" job spells in careers with certain 
dominant patterns (i.e. a manual position for a couple of months in a career dominated by non-manual positions), the potential number of variants in occupational careers becomes even larger. From this perspective, the combination of the optimal matching procedure and the clustering method constitutes an effective way to identify common career patterns, as well as typical and atypical paths of occupational mobility.

Yet, this data-reduction process also has limits and costs. We found that the simplification of the distances among trajectories performed by the OMA procedure is not free of error: even when there is a remarkable similarity among occupational trajectories within each cluster, a more detailed view reveals the presence of a few "outliers" within some clusters. Moreover, the reduction of more than one thousand individual trajectories to only twelve common patterns implies by definition that a part of the variance in trajectories is ignored. In our particular case, the differences between the twelve clusters explain $75 \%$ of the total variance in OMA scores. We consider this to be an acceptable number. However, it is reasonable to think that the explained variance would be reduced if we were dealing with an even more heterogeneous data set. Consider, for example, a sequence analysis based on a nationally representative data set, or one including both men's and women's trajectories. Such a sample would either require separate sequence analyses for different groups with common characteristics, thus reducing the comparability between clusters, or a larger number of clusters, thus reducing their utility as input groups for further analysis.

Overall, sequence analysis has proven to be a useful tool for the study of the occupational trajectories of Monterrey men. Certainly, the strength of the method is based on its exploratory power and we must rely on other techniques such as traditional mobility tables or event history analysis to reveal the forces behind different occupational outcomes. However, that does not mean that the outcomes of sequence analyses cannot be used in further research as independent or dependent variables. As Abbott and Hrycak (1990, p.171) point out, that ultimately depends on the kinds of 
questions we ask. If our interest is to find out why certain kinds of individuals follow specific careers or how certain career patterns affect future outcomes - not only in occupational lives, but also in aspects such as political affiliation, cultural consumption, or life-styles - then sequence analysis might prove to be a very useful tool in future stratification and mobility research.

\section{References}

Abbott, Andrew. 1995. "Sequence Analysis: New Methods for Old Ideas." Annual Review of Sociology 21:93-113.

Abbott, Andrew and Alexandra Hrycak. 1990. "Measuring Resemblance in Sequence Data: An Optimal Matching Analysis of Musicians' Careers." American Journal of Sociology 96(1):144-85.

Abbott, Andrew and Angela Tsay. 2000. "Sequence Analysis and Optimal Matching Methods in Sociology." Sociological Methods and Research 29(1).

Alarcón, Diana. 1994. Changes in the Distribution of Income in México and Trade Liberalization. Tijuana: El Colegio de la Frontera Norte.

Balán, Jorge, Harley L. Browning, and Elizabeth Jelin. 1973. Men in a Developing Society Geographic and Social Mobility in Monterrey, Mexico. Austin: Published for the Institute of Latin American Studies by the University of Texas Press.

Behrman, Jere R., Alejandro Gaviria, and Miguel Székely. 2001. "Intergenerational Mobility in Latin America." Economia 2(1).

Beneria, Lourdes. 1989. "Subcontracting and Employment Dynamics in Mexico City." in The Informal Economy Studies in Advanced and Less Developed Countries, eds. Alejandro Portes, Manuel Castells, and Lauren A. Benton. Baltimore, Md: Johns Hopkins University Press.

Bernardi, Fabrizio. 2000. "Educational Performance and Educational Returns at Entry into the Italian Labor Market." Globalife Project, Working Paper \# 10. University of Bielefeld, Bielefeld, Germany. Available online at http://alia.soziologie.uni-bielefeld.de/ globalife/workingp.html.

Billari, Francesco C. (2001). "Sequence Analysis in Demographic Research and Applications." Canadian Studies in Population 28 (2):439-58.

Blair-Loy, Mary. 1999. "Career Patterns of Executive Women in Finance: An Optimal Matching Analysis ." American Journal of Sociology 104(5):1346-97. 
Blossfeld, Hans-Peter, Alfred Hamerle, and Karl U. Mayer. 1989. Event History Analysis Statistical Theory and Application in the Social Sciences. Hillsdale, N.J: L. Erlbaum Associates.

Blossfeld, Hans-Peter and Götz Rohwer. 2002. Techniques of Event History Modeling. 2nd ed. Mahwah, NJ: Lawrence Erlbaum Associates.

Boltvinik, Julio and Enrique Hernández Laos. 1999. Pobreza y Distribución Del Ingreso En México. México, D.F.: Siglo XXI Editores.

Camerer, C. 1995. "Individual Decision Making." in The Handbook of Experimental Economics, eds. J. H. Kagel and A. E. Roth. Princeton, NJ: Princeton University Press.

Cerutti, Mario. 1992. Burguesía, Capitales e Industria En El Norte De México Monterrey y Su Ámbito Regional (1850-1910). 1. ed ed. México: Alianza Editorial. Facultad de Filosofía y Letras de la Universidad Autónoma de Nuevo León.

- 2000. Propietarios, Empresarios y Empresa En El Norte De México Monterrey: De 1848 a La Globalización. 1. ed ed. México, D.F: Siglo Veintiuno Editores.

Chan, Tak W. 1995. "Optimal Matching Analysis: A Methodological Note on Studying Career Mobility." Work and Occupations 22 :467-90.

Clausen, Sten-Erik. 1998. Applied Correspondence Analysis an Introduction. Thousand Oaks, CA: Sage Publications.

Clavijo, Fernando and Susana Valdivieso. 2000. Reformas Estructurales y Política Macroeconómica: El Caso De México 1982-1999. Serie Reformas Económicas, n. 67. Santiago: CEPAL. División de desarrollo económico.

CONAPO. 2001. La Situación Demográfica De México 2000. México D.F.: Consejo Nacional de Población.

Cortés, Fernando. 1998. "Eficiencia y Desigualdad. Un Contrapunto." Espiral: Estudios Sobre Estado y Sociedad 4(12):169-200.

Cross, John C. 1998. "The Informal Sector." in Encyclopedia of Political Economy, ed Philip O'Hara. London: Routledge.

Deaton, Angus and John Muellbauer. 1980. Economics and Consumer Behavior. Cambridge, New York: Cambridge University Press.

DiPrete, Thomas A., Paul M. De Graff, Ruud Luijkx, Michael Tåhlin, and Hans-Peter Blossfeld. 1997. "Collectivist Versus Individualist Mobility Regimes? Structural 
Change and Job Mobility in Four Countries." American Journal of Sociology 103(2):318-58.

DiPrete, Thomas A., Dominique Goux, Eric Maurin, and Michael Tåblin. 2001. "Institutional Determinants of Employment Chances. The Structure of Unemployment in France and Sweden." European Sociological Review 17(3):233-54.

Elder, Glen H. 1985. Life Course Dynamics Trajectories and Transitions, 1968-1980. Ithaca: Cornell University Press.

Erikson, R. and J. H. Goldthorpe. 1992. The Constant Flux: A Study of Class Mobility In Industrial Societies. Oxford: Clarendon Press.

Escobar, Agustín. undated. "Nuevos Modelos Económicos En México ¿Nuevos Sistemas De Movilidad Social?" Manuscript .

Everitt, Bryan S. 1993. Cluster Analysis. London: E. Arnold.

Giddens, Anthony. 1991. Modernity and Self-Identity Self and Society in the Late Modern Age. Stanford, Calif: Stanford University Press.

González de la Rocha, Mercedes. 1994. The Resources of Poverty Women and Survival in a Mexican City. Oxford, UK, Cambridge, USA: Blackwell.

Gordon, A. D. 1999. Classification. 2nd ed ed. Boca Raton: Chapman \& Hall/CRC.

Halpin, Brendam and Tak W. Chan. 1998. "Class Careers As Sequences: An Optimal Matching Analysis of Work-Life Histories." European Sociological Review 14(2):113-30.

Ham, Roberto. 1993. ""Envejecimiento Demográfico y Seguridad Social. La Insuficiencia De Las Pensiones Por Vejez"." Demos. Carta Demográfica Sobre México 6.

Hauser, Robert M. 1998. "Intergenerational Economic Mobility in the United States. Measures, Differentials and Trends." Working Paper. Madison: University of Wisconsin-Madison.

Heckhausen, J. 1999. Developmental Regulation in Adulthood. Age-Normative and Sociostructural Constraints As Adaptive Challenges. UK: Cambridge University Press.

Klein, Emilio and Víctor E. Tokman. 2000. "Social Stratification Under Tension in a Globalized Era." CEPAL Review 72:7-29.

Koch, Max. 1999. "Changes in the Chilean Social Structure." European Review of Latin American and Caribbean Studies 66(June):5-18. 
Mayer, Karl U. 2001. "The Paradox of Global Social Change and National Path Dependencies. Life Course Patterns in Advanced Societies. " in Inclusions and Exclusions in European Societies, eds. Alison Woodward and Martin Kohli. New York: Routledge.

Muñoz, Humberto, Orlandina d. Oliveira, and Claudio Stern. 1977. Migración y Desigualdad Social En La Ciudad De México. 1. ed ed. México: Instituto de Investigaciones Sociales, Universidad Nacional Autónoma de Mexico.

OECD. 2001. Education at a Glance. Paris: Organization for Economic Co-operation and Development.

Partida Bush, Virgilio. 1994. Migración Interna. Aguascalientes, Ags, México, D.F.: Instituto Nacional de Estadística, Geografía e Informática. El Colegio de México. Instituto de Investigaciones Sociales, Universidad Nacional Autónoma de México.

Portes, Alejandro, Manuel Castells, and Lauren A. Benton. 1989. The Informal Economy Studies in Advanced and Less Developed Countries. Baltimore, Md: Johns Hopkins University Press.

Pozas, María d. 1. A. 1993. Industrial Restructuring in Mexico Corporate Adaptation, Technological Innovation, and Changing Patterns of Industrial Relations in Monterrey. La Jolla, CA: Published by the Center for U.S.-Mexican Studies, UCSD in association with El Colegio de la Frontera Norte.

_ 1999. "Mexican Firms in the New Global Economy." Doctoral Dissertation, Johns Hopkins University, Baltimore.

Pozos Ponce, Fernando. 1996. Metrópolis En Reestructuración. Guadalajara y Monterrey, 1980-1989. 1. ed ed. Guadalajara, Jalisco, Mxico: Universidad de Guadalajara.

Rakowski, Cathy A. 1994. Contrapunto the Informal Sector Debate in Latin America. Albany: State University of New York Press.

Roberts, Bryan R. 1989. "Employment Structure, Life Cycle, and Life Chances: Formal and Informal Sectors in Guadalajara." in The Informal Economy Studies in Advanced and Less Developed Countries, eds. Alejandro Portes, Manuel Castells, and Lauren A. Benton. Baltimore, Md: Johns Hopkins University Press.

Roberts, Bryan R. and Orlandina d. Oliveira. 1994. "Urban Growth and Urban Social Structure in Latin America 1930-1990." in The Cambridge History of Latin America, vol. VI, ed. Leslie Bethel. Cambridge: Cambridge University Press.

Rohwer, G. and H. Trappe. 1999. "Possibilities and Difficulties in Life Course Description." Pp. 146-67 in Dynamic Approaches to Comparative Social 
Research. Recent Developments and Applications, ed. W. Voges. Aldershot: Avebury Publishers.

Rohwer, Götz and Pöter, Ulrich. 1999. "TDA user's manual" [Web Page]. Available at http://www.stat.ruhr-uni-bochum.de/.

Sankoff, D. and J. B. Kruskal, eds. 1983. Time Warps, String Edits, and Macromolecules: the Theory and Practice of Sequence Comparison. Reading, MA: Addison-Wesley.

Scherer, Stefani. 2001. "Early Career Patterns: A Comparison of Great Britain and West Germany." European Sociological Review 17(2):119-44.

Selby, Henry A., Arthur D. Murphy, and Stephen A. Lorenzen. 1990. The Mexican Urban Household Organizing for Self-Defense. 1st ed ed. Austin: University of Texas Press.

Shavit, Yossi, Judah Matras, and David L. Featherman. 1990. "Job Shifts in the Career Beginnings of Isreaeli Men." in Event History Analysis in Life Course Research, . Karl U. Mayer and Nancy B. Tuma. Madison: The University of Wisconsin Press.

Smith, William C. and Roberto P. Korzeniewicz. 1997. Politics, Social Change, and Economic Restructuring in Latin America. Coral Gables, Fla, Boulder, CO: North-South Center Press. distributed by Lynne Rienner Publishers.

Solís, Patricio. 1996. "El Retiro Como Transición a La Vejez En México." Pp. .261-95 in Los Retos De La Población, ed. Cecilia Rabell. México, D.F.: Facultad Latinoamericana de Ciencias Sociales. 1997. "Cambios En El Crecimiento De La Población Urbana y De La Población Rural." Demos. Carta Demográfica Sobre México 10.

(draft). "Job Mobility, Occupational Careers and Social Change in Monterrey, México." Doctoral Dissertation in Sociology (Expected Submission Date: Fall 2002), Austin: University of Texas at Austin.

Sørensen, Aage B. 1990. "Employment Sector and Unemployment Processes." in Event History Analysis in Life Course Research, . Karl U. Mayer and Nancy B. Tuma. Madison: The University of Wisconsin Press.

Statistics Canada. 1999. BioBrowser: The ModGen Biography Browser. Users Guide. Version 3.1. Ottawa: Statistics Canada.

Tuirán, Rodolfo. 1993. "Las Respuestas De Los Hogares De Sectores Populares Urbanos Frente a La Crisis: El Caso De La Ciudad De México." in Población y Desigualdad Social En México, 1a. ed ed. Raúl Béjar Navarro, Héctor Hernández Bringas, and Anne Bar-Din. Cuernavaca, Mor: Universidad Nacional Autónoma de México, Centro Regional de Investigaciones Multidisciplinarias. 
Waterman, M. S. 1995. Introduction to Computational Biology. Maps, Sequences and Genomes. London and New York: Chapman \& Hall.

Wehner, S. 1999. "Exploring and Visualizing Event History Data." in Materialien Aus Der Bildungsforschung Nr. 65., Berlin: Max-Planck-Institut für Bildungsforschung.

Weller, Susan C. and A. K. Romney. 1990. Metric Scaling Correspondence Analysis. Newbury Park, Calif: Sage Publications.

World Bank, ADB, IADB, IMF, and EBRD. 2001. "A Globalized Market . Opportunities and Risks for the Poor." Prepared for the G8 Genoa Summit. http://www.worldbank.org/poverty/library/G8_2001.pdf.

Wu, Lawrence L. 2000. "Some Comments on 'Sequence Analysis and Optimal Matching Methods in Sociology'." Sociological Methods and Research 29(1):41-64. 


\section{List of captions}

Table 1. Classification of Occupations

Table 2. Matrix of Substitution Costs

Table 3. Variance Explained by the First 20 Partitions of the Sample in Clusters of Proximate Occupational Sequences. Ward's Minimum Variance Clustering Method

Table 4. Quartiles and Median of Age at First Job for Monterrey Men, According to Selected Characteristics. Kaplan-Meier Estimates

Table 5. First Occupation After Age 14 and Occupational Mobility Between First Occupation and Occupation at Age 30 for Monterrey Men

Table 6. Career Patterns of Monterrey Men

Table 7. Principal Characteristics of the Career Patterns of Monterrey Men

Table 8. Distribution of Men with Selected Social and Demographic Characteristics by Occupational Trajectory (\%)

Figure 1. Occupational Trajectories Between Ages 14 and 30 for Monterrey Men, According to their Cluster Membership

Figure 2. Birth Cohorts, Father Background, Education, and Clusters of Occupational Careers. Correspondence Analysis Plot 


\section{Tables and figures}

Table 1. Classification of Occupations

\section{Managers \& Professionals}

- All professional occupations

- High-level managers, public and private sectors

- College Professors

\section{Skilled Non-Manual Workers}

- Technicians and specialized personnel

- Professors in all levels but College

- Arts \& Sports workers

- Middle-level supervisors in clerical activities (department heads)

- Owners of sales businesses

III. Clerical Workers \& Sales Agents

- Clerical workers (secretaries, archivists, etc)

- Sales agents (insurance, real state, etc.)

\section{Sales Employees \& Control Workers}

- Supervisors and inspectors in industry

- Sales employees in established businesses

\section{Skilled manual workers}

- Machine operatives and craftsmen, except construction workers

- Specialized manual workers, except construction workers

- Vehicle conductors

\section{Unskilled Manual Workers}

- Unskilled industrial workers ("peones", helpers) and all construction workers

\section{Unskilled Workers in Personal Services}

- Street sales workers

- Personal service workers

- Domestic service workers

- Security workers

VIII. Farm workers

- All Workers in farm activities 
Table 2. Matrix of Substitution Costs

\begin{tabular}{|c|c|c|c|c|c|c|c|c|c|c|}
\hline & $\mathrm{N}^{\mathrm{a}}$ & I & II & III & IV & V & VI & VII & VIII & $\mathrm{O}^{\mathrm{b}}$ \\
\hline $\mathrm{N}^{\mathrm{a}}$ & 0 & 6 & 6 & 6 & 6 & 6 & 6 & 6 & 6 & 6 \\
\hline I & & 0 & 2 & 2 & 2 & 4 & 5 & 5 & 6 & 6 \\
\hline II & & & 0 & 1 & 1 & 3 & 4 & 4 & 5 & 6 \\
\hline III & & & & 0 & 1 & 3 & 4 & 4 & 5 & 6 \\
\hline IV & & & & & 0 & 3 & 4 & 4 & 5 & 6 \\
\hline V & & & & & & 0 & 2 & 2 & 3 & 6 \\
\hline VI & & & & & & & 0 & 1 & 2 & 6 \\
\hline VII & & & & & & & & 0 & 2 & 6 \\
\hline VIII & & & & & & & & & $\overline{0}$ & 6 \\
\hline $\mathrm{O}^{\mathrm{b}}$ & & & & & & & & & & 0 \\
\hline
\end{tabular}

a. Not yet in the Labor Force

b. Temporarily Out of the Labor Force 
Table 3. Variance Explained by the First 20 Partitions of the Sample in Clusters of Proximate Occupational Sequences. Ward's Minimum Variance Clustering Method

\begin{tabular}{cccc}
$\begin{array}{c}\text { Number of } \\
\text { Clusters }\end{array}$ & $\begin{array}{c}\text { Frequency } \\
\text { of New Cluster }\end{array}$ & $\begin{array}{c}\text { Semipartial } \\
\text { R-Squared }\end{array}$ & R- Squared \\
1 & 1019 & 0.425 & 0.000 \\
2 & 481 & 0.124 & 0.425 \\
3 & 538 & 0.050 & 0.549 \\
4 & 292 & 0.036 & 0.599 \\
5 & 269 & 0.026 & 0.635 \\
6 & 246 & 0.024 & 0.661 \\
7 & 209 & 0.017 & 0.685 \\
8 & 174 & 0.016 & 0.702 \\
9 & 141 & 0.014 & 0.719 \\
10 & 212 & 0.013 & 0.733 \\
11 & 155 & 0.013 & 0.746 \\
\hline $\mathbf{1 2}$ & $\mathbf{8 3}$ & $\mathbf{0 . 0 1 2}$ & $\mathbf{0 . 7 5 9}$ \\
\hline 13 & 179 & 0.009 & 0.771 \\
14 & 95 & 0.008 & 0.781 \\
15 & 42 & 0.007 & 0.788 \\
16 & 84 & 0.007 & 0.796 \\
17 & 19 & 0.006 & 0.803 \\
18 & 119 & 0.005 & 0.809 \\
19 & 99 & 0.005 & 0.814 \\
20 & 115 & 0.004 & 0.819 \\
\hline
\end{tabular}


Table 4. Quartiles and Median of Age at First Job for Monterrey Men, According to Selected Characteristics. Kaplan-Meier

Estimates

\begin{tabular}{|c|c|c|c|}
\hline Variable & Quartile 1 & Median & Quartile 3 \\
\hline
\end{tabular}

Cohort

1940-1949

$\begin{array}{llllll}13.4 & 15.7 & 17.8 & 4.4 & 328 & 21\end{array}$

$1950-1959$

$13.9 \quad 16.2$

18.9

$5.0 \quad 342$

21

1960-1969

14.8

16.8

18.5

$3.7 \quad 349$

32

Respondent's Education

Less Than Primary

11.2

13.5

15.4

4.2

\section{7}

148

4.5

218

Secondary

12.3
14.5

14.9

16.8

2.8

218
176

17.3

3.4

176

$\begin{array}{ll}14.9 & 16.9 \\ 16.3 & 19.2\end{array}$

21.8

5.4

380

47

College

Father's Education

Less than Primary

Primary

$\begin{array}{lll}12.9 & 15.7 & 17.3\end{array}$

$4.4 \quad 441$

441
288

3.2

$\begin{array}{lll}14.8 & 16.6 & 18.0\end{array}$

4.4

168

$\begin{array}{lll}15.6 & 18.2 & 20.0\end{array}$

5.1

120

9

$\begin{array}{lll}17.0 & 20.4 & 22.1\end{array}$

5.1

15

26

21

29

College

Father's Occupation at Birth

Lower Manual

$\begin{array}{lll}13.5 & 15.9 & 17.8\end{array}$

$4.3 \quad 471$

471
240

50

Higher Manual

$\begin{array}{lll}14.3 & 16.6 & 18.1\end{array}$

3.7

240

26

Lower Non-Manual

$14.9 \quad 17.4$

20.0

5.1

218

19

Higher Non-Manual

17.3

21.3

22.6

5.3

85

5

Total

$14.3 \quad 16.5$

18.4

4.1

1019

100

Source: Monterrey Occupational Mobility and Life Course Survey 2000 
Table 5. First Occupation After Age 14 and Occupational Mobility Between First Occupation and Occupation at Age 30 for Monterrey Men

First Occupation

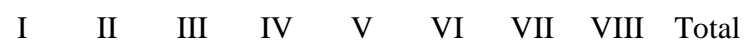

\section{Cohort}

1940-1949

1950-1959

1960-1969

Age at First Occupation

$<14$

$14-16$

$17-19$

$>19$

\section{Father's Education}

Less than Primary

Complete Primary

Any Secondary/Preparatory

Any College

\begin{tabular}{|c|c|c|c|c|c|c|c|}
\hline 3 & 8 & 11 & 10 & 11 & 34 & 17 & 6 \\
\hline 5 & 12 & 10 & 12 & 10 & 32 & 13 & 7 \\
\hline 4 & 11 & 13 & 6 & 13 & 35 & 15 & 4 \\
\hline
\end{tabular}

100
100
100

\begin{tabular}{|c|c|c|c|c|c|c|c|}
\hline 0 & 2 & 7 & 8 & 7 & 33 & 26 & 18 \\
\hline 0 & 4 & 7 & 11 & 11 & 48 & 16 & 3 \\
\hline 1 & 14 & 14 & 6 & 20 & 33 & 11 & 1 \\
\hline 22 & 31 & 21 & 10 & 6 & 7 & 1 & 0 \\
\hline
\end{tabular}

100 100 100 100

\begin{tabular}{|c|c|c|c|c|c|c|c|}
\hline 1 & 7 & 8 & 8 & 11 & 40 & 17 & 9 \\
\hline 3 & 11 & 12 & 8 & 15 & 35 & 13 & 3 \\
\hline 5 & 15 & 15 & 12 & 11 & 28 & 14 & 1 \\
\hline 20 & 27 & 15 & 12 & 6 & 9 & 11 & 0 \\
\hline
\end{tabular}

100 100 100 100

Father's Occupation at

\section{Birth}

Lower Manual

Higher Manual

Lower Non-Manual

Higher Non-Manual

Respondent's Education

Less Than Primary

Complete Primary

Any Secondary

Any Preparatory

Any College

\begin{tabular}{|c|c|c|c|c|c|c|c|}
\hline 2 & 7 & 7 & 6 & 11 & 39 & 17 & 10 \\
\hline 3 & 10 & 13 & 9 & 15 & 38 & 12 & 1 \\
\hline 6 & 16 & 19 & 13 & 9 & 23 & 13 & 1 \\
\hline 22 & 35 & 14 & 14 & 4 & 4 & 7 & 0 \\
\hline
\end{tabular}

100
100
100
100

\begin{tabular}{|c|c|c|c|c|c|c|c|}
\hline 0 & 2 & 5 & 3 & 6 & 40 & 24 & 20 \\
\hline 0 & 1 & 7 & 2 & 13 & 45 & 18 & 13 \\
\hline 0 & 4 & 6 & 11 & 15 & 48 & 13 & 3 \\
\hline 0 & 8 & 14 & 9 & 16 & 36 & 15 & 2 \\
\hline 13 & 27 & 18 & 12 & 6 & 13 & 11 & 0 \\
\hline
\end{tabular}

100

100

100

100

100

$\begin{array}{lllllllll}4 & 11 & 11 & 9 & 12 & 34 & 14 & 5 & 100\end{array}$
Mobility by Age $30^{*}$

LU SU NM SD LD Total

\begin{tabular}{|l|l|l|l|l|}
\hline 19 & 35 & 33 & 8 & 4 \\
\hline 19 & 38 & 34 & 4 & 5 \\
\hline 20 & 34 & 32 & 7 & 6 \\
\hline
\end{tabular}

100

100

\begin{tabular}{|c|c|c|c|c|}
\hline 25 & 43 & 23 & 5 & 3 \\
\hline 21 & 36 & 30 & 8 & 5 \\
\hline 22 & 28 & 36 & 6 & 8 \\
\hline 6 & 34 & 51 & 4 & 4 \\
\hline
\end{tabular}

100

100

100

100

\begin{tabular}{|l|l|l|l|l|}
\hline 17 & 37 & 34 & 7 & 5 \\
\hline 18 & 34 & 33 & 6 & 8 \\
\hline 30 & 36 & 28 & 4 & 2 \\
\hline 25 & 32 & 39 & 3 & 2 \\
\hline
\end{tabular}

100

100

100

100

\begin{tabular}{|l|l|l|l|l|}
\hline 20 & 36 & 33 & 6 & 5 \\
\hline 18 & 38 & 30 & 8 & 7 \\
\hline 23 & 26 & 40 & 6 & 5 \\
\hline 11 & 54 & 33 & 2 & 1 \\
\hline
\end{tabular}

100

100

100

100

\begin{tabular}{|c|c|c|c|c|}
\hline 7 & 47 & 38 & 5 & 3 \\
\hline 15 & 41 & 32 & 6 & 6 \\
\hline 19 & 30 & 34 & 11 & 6 \\
\hline 25 & 34 & 30 & 7 & 4 \\
\hline 24 & 35 & 34 & 2 & 6 \\
\hline
\end{tabular}

100 100 100 100 100

$\begin{array}{lllll}20 & 35 & 33 & 6 & 5\end{array}$

100

* LU - Long-upward mobility; SU - Short Upward Mobility; NM - No vertical mobility; SD - Short Downward Mobility;

LD - Long Downward Mobility

Source: Monterrey Occupational Mobility and Life Course Survey 2000 
Table 6. Career Patterns of Monterrey Men

\begin{tabular}{|c|c|c|}
\hline Career Pattern & $\%$ & Cases \\
\hline 1. Early unskilled manual & 11.3 & 105 \\
\hline 2. Early skilled manual & 12.9 & 119 \\
\hline 3. Unskilled manual & 11.2 & 99 \\
\hline 4. Skilled manual & 10.6 & 90 \\
\hline 5 Long Upward Mobility & 9.3 & 83 \\
\hline Teenage white-collar & 9.1 & 95 \\
\hline 7 Long Downward Mobility & 4.6 & 42 \\
\hline Clerical & 10.6 & 115 \\
\hline 9. Professionals \& managers & 13.7 & 179 \\
\hline 10. Professionals $\&$ managers with early entry & 2.6 & 40 \\
\hline 11. Late entry & 2.6 & 33 \\
\hline 12. Intermittent & 1.5 & 19 \\
\hline
\end{tabular}

Source: Monterrey Occupational Mobility and Life Course Survey 2000 
Table 7. Principal Characteristics of the Career Patterns of Monterrey Men

a. Age at first occupation and first occupation after age 14

\begin{tabular}{|c|c|c|c|c|}
\hline \multirow[b]{2}{*}{ "Typical" trajectory } & \multicolumn{4}{|c|}{ Age at first occupation } \\
\hline & Q1 & $\mathrm{Q} 2$ & Q3 & Q3-Q1 \\
\hline 1. Early unskilled manual & 10.1 & 12.9 & 14.4 & 4.3 \\
\hline 2. Early skilled manual & 12.4 & 14.5 & 15.6 & 3.2 \\
\hline 3. Unskilled manual & 16.3 & 17.0 & 18.0 & 1.7 \\
\hline 4. Skilled manual & 17.0 & 17.7 & 18.4 & 1.4 \\
\hline 5 Long Upward Mobility & 13.4 & 16.0 & 17.1 & 3.7 \\
\hline 6 Teenage white-collar & 11.7 & 14.5 & 15.0 & 3.3 \\
\hline 7 Long Downward Mobility & 11.8 & 16.1 & 16.9 & 5.1 \\
\hline 8 Clerical & 17.0 & 17.8 & 18.7 & 1.7 \\
\hline 9. Professionals \& managers & 20.8 & 21.7 & 22.8 & 1.9 \\
\hline 10. Professionals \& managers with early ent & 13.9 & 15.7 & 17.1 & 3.2 \\
\hline 11. Late entry & 24.8 & 25.3 & 26.1 & 1.3 \\
\hline 12. Intermittent & 16.9 & 17.8 & 18.9 & 2.0 \\
\hline
\end{tabular}

\begin{tabular}{ccccccccc}
\multicolumn{10}{c}{ First occupation after age 14 } \\
\hline I & II & III & IV & V & VI & VII & VIII & Total \\
\hline 0 & 0 & 0 & 1 & 4 & 51 & 22 & 22 & 100 \\
0 & 1 & 5 & 5 & 17 & 56 & 12 & 4 & 100 \\
0 & 0 & 0 & 0 & 12 & 60 & 25 & 3 & 100 \\
0 & 4 & 6 & 3 & 37 & 42 & 7 & 1 & 100 \\
0 & 0 & 3 & 3 & 15 & 39 & 28 & 11 & 100 \\
0 & 8 & 16 & 24 & 4 & 16 & 30 & 3 & 100 \\
0 & 7 & 26 & 28 & 3 & 19 & 8 & 7 & 100 \\
0 & 31 & 27 & 13 & 9 & 17 & 3 & 0 & 100 \\
22 & 36 & 23 & 9 & 3 & 5 & 1 & 0 & 100 \\
2 & 13 & 23 & 25 & 4 & 17 & 17 & 0 & 100 \\
34 & 27 & 14 & 18 & 0 & 4 & 3 & 0 & 100 \\
0 & 5 & 3 & 10 & 16 & 49 & 17 & 0 & 100
\end{tabular}

b. Occupation at age 30 and mobility between first occupation and occupation at age 30

\begin{tabular}{lcccccccccc} 
& \multicolumn{1}{c}{ Occupation at age 30} \\
\cline { 2 - 11 } "Typical" trajectory & I & II & III & IV & V & VI & VII & VIII & O & Total \\
\hline 1. Early unskilled manual & 0 & 1 & 1 & 1 & 11 & 67 & 18 & 0 & 2 & 100 \\
2. Early skilled manual & 0 & 3 & 1 & 0 & 88 & 4 & 2 & 0 & 1 & 100 \\
3. Unskilled manual & 0 & 4 & 5 & 3 & 14 & 51 & 23 & 0 & 0 & 100 \\
4. Skilled manual & 0 & 3 & 0 & 1 & 92 & 0 & 4 & 0 & 0 & 100 \\
5 Long Upward Mobility & 4 & 30 & 16 & 34 & 7 & 5 & 2 & 1 & 1 & 100 \\
6 Teenage white-collar & 12 & 41 & 28 & 12 & 2 & 0 & 2 & 0 & 2 & 100 \\
7 Long Downward Mobility & 0 & 7 & 0 & 0 & 48 & 23 & 22 & 0 & 0 & 100 \\
8 Clerical & 9 & 37 & 36 & 16 & 1 & 0 & 0 & 0 & 0 & 100 \\
9. Professionals \& managers & 50 & 28 & 8 & 7 & 4 & 1 & 0 & 0 & 2 & 100 \\
10. Professionals \& managers with early ent & 100 & 0 & 0 & 0 & 0 & 0 & 0 & 0 & 0 & 100 \\
11. Late entry & 42 & 14 & 13 & 12 & 15 & 4 & 0 & 0 & 1 & 100 \\
12. Intermittent & 31 & 14 & 10 & 17 & 0 & 0 & 0 & 0 & 27 & 100
\end{tabular}

\begin{tabular}{cccccc}
\multicolumn{7}{c}{ Occupational Mobility } \\
\hline LU & SU & NM & SD & LD & Total \\
\hline 2 & 39 & 51 & 7 & 1 & 100 \\
3 & 68 & 16 & 3 & 10 & 100 \\
13 & 16 & 59 & 12 & 0 & 100 \\
3 & 51 & 31 & 3 & 12 & 100 \\
78 & 10 & 8 & 4 & 0 & 100 \\
49 & 26 & 19 & 4 & 1 & 100 \\
6 & 26 & 8 & 0 & 60 & 100 \\
28 & 25 & 38 & 9 & 0 & 100 \\
5 & 44 & 44 & 5 & 2 & 100 \\
38 & 60 & 2 & 0 & 0 & 100 \\
4 & 17 & 57 & 5 & 16 & 100 \\
78 & 16 & 6 & 0 & 0 & 100
\end{tabular}

Source: Monterrey Occupational Mobility and Life Course Survey 2000 
Table 8. Distribution of Men with Selected Social and Demographic Characteristics by Occupational Trajectory $(\%)$

Cohort

1940-1949

1950-1959

1960-1969

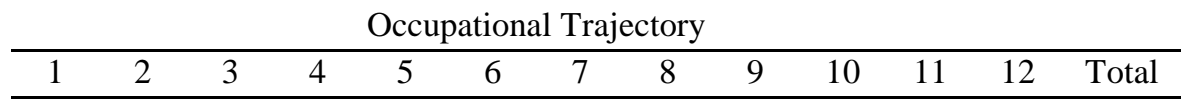

$\begin{array}{ccccccccccccc}15 & 16 & 12 & 7 & 10 & 9 & 5 & 10 & 8 & 2 & 3 & 2 & 100 \\ 12 & 13 & 9 & 8 & 7 & 12 & 4 & 11 & 16 & 4 & 3 & 1 & 100 \\ 9 & 11 & 12 & 14 & 11 & 8 & 5 & 11 & 14 & 2 & 2 & 2 & 100\end{array}$

Father's Occupation at Birth

Lower Manual

Higher Manual

Lower Non-Manual

Higher Non-Manual

$\begin{array}{ccccccccccccc}17 & 15 & 14 & 11 & 13 & 6 & 5 & 7 & 9 & 1 & 1 & 1 & 100 \\ 9 & 18 & 9 & 13 & 6 & 10 & 5 & 11 & 11 & 2 & 3 & 2 & 100 \\ 2 & 3 & 9 & 7 & 7 & 18 & 4 & 17 & 21 & 4 & 4 & 3 & 100 \\ 0 & 1 & 0 & 3 & 0 & 3 & 1 & 15 & 54 & 10 & 8 & 6 & 100\end{array}$

\section{Father's Education}

Less than Primary

Primary

Secondary/Preparatory

College

$\begin{array}{ccccccccccccc}18 & 17 & 15 & 11 & 9 & 8 & 6 & 7 & 6 & 1 & 2 & 1 & 100 \\ 8 & 15 & 11 & 14 & 10 & 9 & 4 & 11 & 12 & 2 & 2 & 1 & 100 \\ 3 & 5 & 8 & 9 & 11 & 10 & 3 & 17 & 21 & 8 & 4 & 2 & 100 \\ 0 & 0 & 0 & 0 & 6 & 12 & 2 & 16 & 48 & 5 & 7 & 3 & 100\end{array}$

Father's Occupation and

Education

LM / Primary or Less

HM / Primary or Less

LNM / Secondary or More

HNM / College

LM / Secondary or More

HM / Secondary or More

LNM / Primary or Less

HNM / Secondary or Less

$\begin{array}{ccccccccccccc}18 & 17 & 15 & 11 & 12 & 5 & 4 & 6 & 9 & 1 & 1 & 1 & 100 \\ 10 & 19 & 11 & 15 & 4 & 9 & 6 & 10 & 9 & 2 & 3 & 1 & 100 \\ 0 & 0 & 6 & 2 & 5 & 14 & 2 & 21 & 36 & 9 & 5 & 1 & 100 \\ 0 & 0 & 0 & 0 & 0 & 1 & 0 & 7 & 66 & 10 & 10 & 7 & 100 \\ 3 & 1 & 9 & 15 & 18 & 10 & 6 & 15 & 12 & 6 & 5 & 1 & 100 \\ 6 & 12 & 4 & 4 & 15 & 15 & 2 & 18 & 18 & 2 & 2 & 3 & 100 \\ 4 & 6 & 12 & 10 & 8 & 22 & 6 & 15 & 9 & 1 & 4 & 4 & 100 \\ 0 & 2 & 0 & 15 & 0 & 9 & 4 & 37 & 17 & 10 & 2 & 2 & 100\end{array}$

\section{Respondent's Education}

Less Than Primary

Primary

Secondary

Preparatory

College

$\begin{array}{ccccccccccccc}42 & 18 & 12 & 5 & 7 & 4 & 6 & 2 & 1 & 0 & 1 & 1 & 100 \\ 24 & 22 & 13 & 11 & 9 & 7 & 8 & 2 & 2 & 0 & 0 & 0 & 100 \\ 11 & 18 & 18 & 15 & 11 & 8 & 7 & 9 & 2 & 1 & 1 & 0 & 100 \\ 4 & 15 & 13 & 19 & 10 & 12 & 6 & 13 & 6 & 0 & 1 & 1 & 100 \\ 1 & 1 & 3 & 2 & 8 & 11 & 0 & 17 & 40 & 8 & 7 & 4 & 100\end{array}$

Source: Monterrey Occupational Mobility and Life Course Survey 2000 
Figure 1. Occupational Trajectories Between Ages 14 and 30 for Monterrey Men, According to Their Cluster Membership*

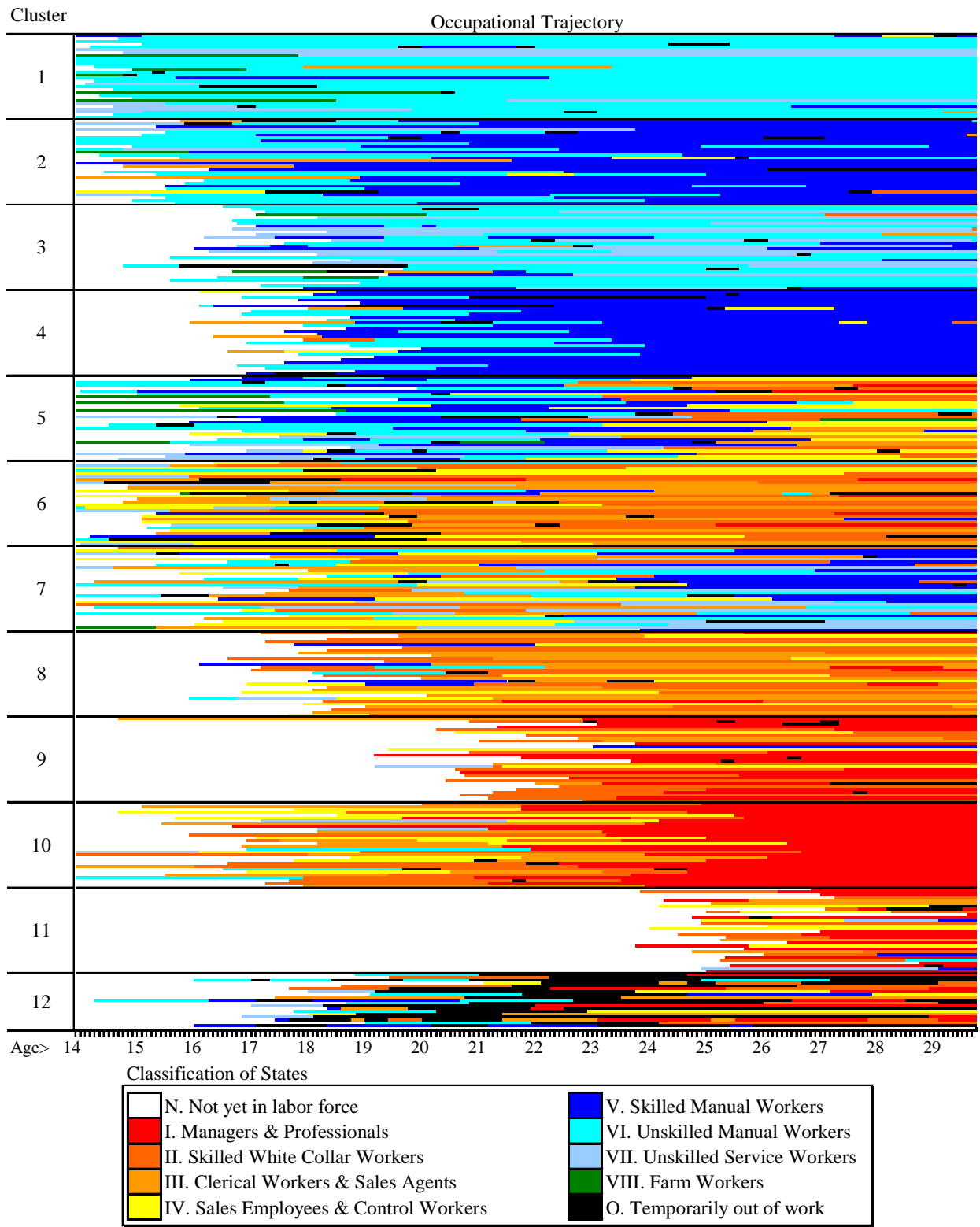

* A random sample with 30 cases is displayed for clusters with more than 30 cases Source: Monterrey Occupational Mobility and Life Course Survey 2000

Age 
Figure 2. Birth Cohorts, Father Background, Education, and Clusters of Occupational Careers. Correspondence Analysis Plot

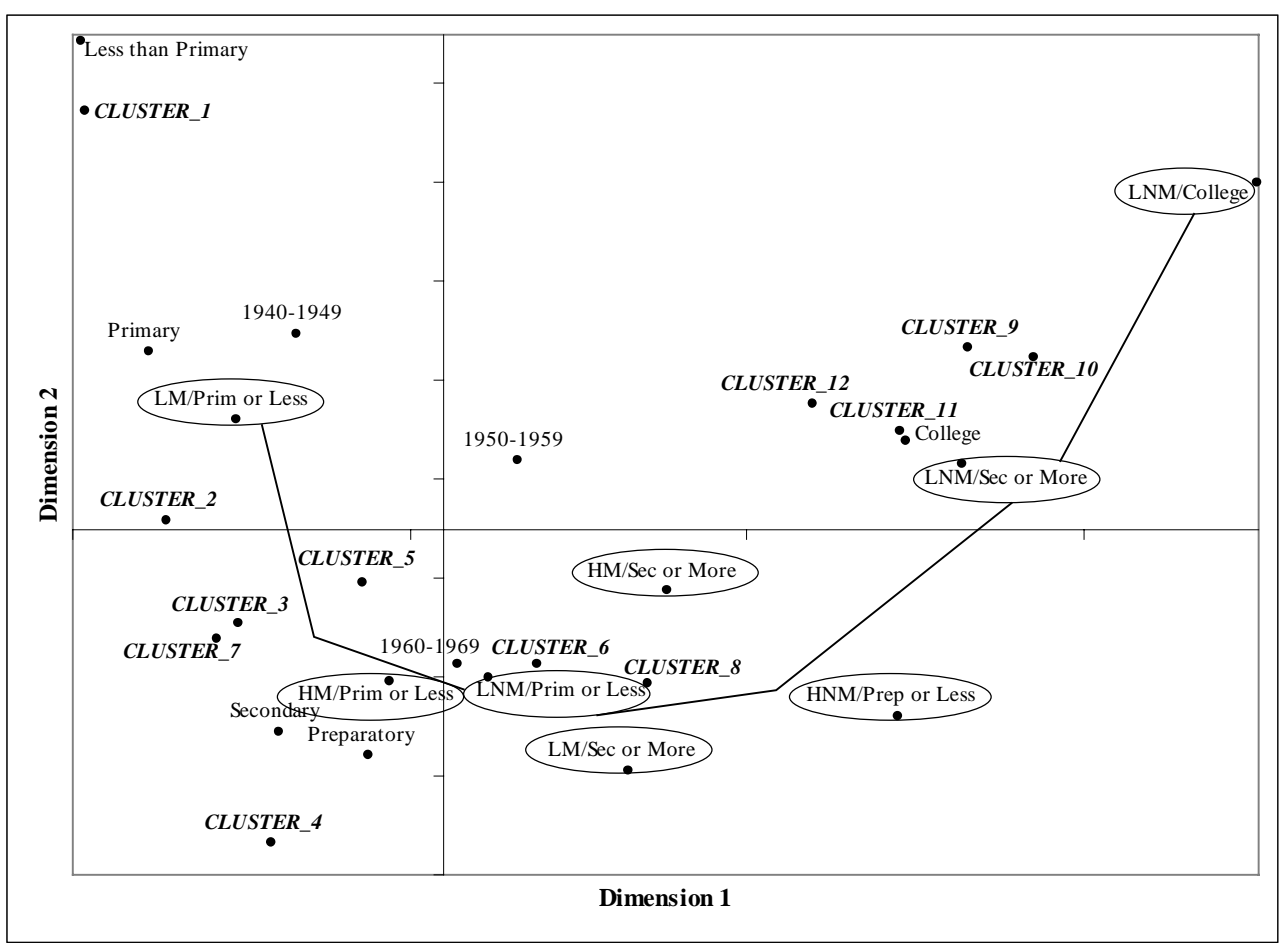

Source: Monterrey Occupational Mobility and Life Course Survey 2000 